\title{
Source of nitrogen as a factor limiting saponin production by hairy root and suspension cultures of Calendula officinalis L.
}

\author{
Marek Długosz $^{1}$ (1) $\cdot$ Michał Markowski $^{1} \cdot$ Cezary Pączkowski ${ }^{1}$
}

Received: 26 June 2017 / Revised: 23 October 2017 / Accepted: 9 January 2018 / Published online: 19 January 2018

(c) The Author(s) 2018. This article is an open access publication

\begin{abstract}
Triterpenic saponins represented in Calendula officinalis L. by oleanolic acid (OA) glycosides are pentacyclic triterpene compounds with a wide range of biological and medicinal properties. This report demonstrates nitrogen source impact on growth, saponin accumulation, and secretion in hairy root and suspension cultures of marigold. Hairy roots preferred nitrate as a mineral source of nitrogen, but its impact on growth, OA glycosides accumulation, and secretion were line-dependent. The best productivity of OA glycosides was found in CC16 line $\left(74.86 \mathrm{mg}_{\text {flask }}{ }^{-1}\right)$ in $1 / 2 \mathrm{MS}$ medium modified by $2.5 \times \mathrm{KNO}_{3}$ and ammonium elimination with $2.5 \mathrm{~g} \mathrm{l}^{-1}$ peptone. Organic nitrogen source at $27.5-\mathrm{g} \mathrm{l}^{-1}$ impairs the growth rate of hairy roots. Its effect on saponin accumulation and secretion to the surrounding medium depended on line and media composition. Nitrate:ammonium ratio of 4:2 for CC16 resulted in 5.7-fold increment of saponin secretion comparing to the standard medium. Embryo roots, apical bud, and hypocotyls explants were crucial for induction of suspension culture synthesizing saponins; however, effect of mineral form of nitrogen in cultivating medium had to be considered. The highest OA glycosides level (171.97 $\mu \mathrm{g} \mathrm{g}^{-1}$ of dry weight) was recorded in the root derived culture with nitrate as a sole mineral form of nitrogen. Peptone from lactalbumin decidedly inhibited the saponin formation; however, it was essential for culture initiation, proliferation, and organ differentiation.
\end{abstract}

Keywords Nitrogen $\cdot$ Saponins $\cdot$ Oleanolic acid $\cdot$ Hairy roots $\cdot$ Suspension culture $\cdot$ Marigold

\begin{tabular}{|c|c|}
\hline \multicolumn{2}{|c|}{ Abbreviations } \\
\hline 2,4-D & 2,4-Dichlorophenoxyacetic acid \\
\hline $\mathrm{SC}$ & Suspension culture \\
\hline HR & Hairy root culture \\
\hline OA & Oleanolic acid \\
\hline B & Bud \\
\hline $\mathrm{C}$ & Cotyledon \\
\hline $\mathrm{H}$ & Hypocotyl \\
\hline $\mathrm{R}$ & Root \\
\hline PCV & Packed cell volume \\
\hline TLC & Thin-layer chromatography \\
\hline GLC & Gas-liquid chromatography \\
\hline FID & Flame ionization detector \\
\hline MS & Murashige and Skoog (1962) media \\
\hline
\end{tabular}

Communicated by A. Krolicka.

Marek Długosz

mdlugosz@biol.uw.edu.pl

1 Department of Plant Biochemistry, Faculty of Biology, University of Warsaw, Miecznikowa 1, 02-096 Warsaw, Poland

\section{Introduction}

Oleanolic acid (OA) naturally occurs in plants as the form of glycosidic derivatives is a pentacyclic triterpenoid which has been identified in more than 1620 of edible and medicinal species (Fai and Tao 2009; Fukushima et al. 2011). This compound is widely distributed among the olive family (Oleaceae) and its name originated form olives Olea europaea (Simonsen and Ross 1957). Oleanolic acid in free form is hydrophobic and has numerous pharmacological properties including anti-tumor, anti-HIV, hepatoprotective, immunostimulatory, or anti-inflammatory (Laszczyk 2009; Kashiwada et al. 1998; Wang et al. 2010; Rios 2010). Other specific biological activity of OA molecules is associated with sugar chain linked to the aglycone with glycosidic bond. These complex structures, called saponins, have a better solubility in water and exhibit hemolytic, allelopathic, fungistatic (Szakiel et al. 2005), antibacterial, and antiparasitic properties (Szakiel et al. 2008; Doligalska et al. 2011). Those significant bio-activities and relatively nontoxic nature have made oleanolic acid a highly valuable compound. Novel research opportunities for cancer therapy were 
opened by the synthetic derivatives of OA. This modification consists of introducing cyano-, methyl-, or imidazole substituent to harvest from biological sources triterpene backbone. Improved molecules effectively induced apoptosis in different cancer cell lines and suppressed tumor growth in vivo (Liby et al. 2007; Deeb et al. 2008; Sporn et al. 2011). Latest important discoveries were Himoxol (ethyl 3-hydroxyimino11-oxoolean-12-en-28-oate), semisynthetic OA derivative reported to exert its cytotoxic action in breast cancer cells by activating apoptosis and autophagy pathways (Lisiak et al. 2014) and PFOA (3-O-[N-(p-fluorobenzenesulfonyl)carbamoyl]-oleanolic acid) which, apart from antiproliferative action, shows the ability to inhibit invasive breast cancer by preventing the cell migration and metastasis (Elsayed et al. 2015).

The molecule of OA is obtained solely from biological sources by laborious extraction and purification. Despite the considerable difficulty, the mentioned procedure has been carried on with satisfactory performance. There is still a risk of obtaining the plant material with low level of desired products. Their concentration in intact plants is affected by plenty environmental factors (Szakiel et al. 2011). An alternative source of oleanolic acid glycosides can be in vitro culture of marigold, with possibility of obtaining the line with stable contents of desired compounds. In addition, strictly defined conditions of in vitro culture ease studying the impact of different factors separately. Other important advantage is liquid medium which allows to obtain a precise application of the most factors and to simplify gathering of exudates. Both types of cultures used in our study, hairy roots and suspension culture of marigold, are considered as a key to achieve production on commercial scale. They differ in genetic stability and efficiency of metabolite synthesis: hairy root cultures offer higher stability and productivity than suspension culture which is composed of undifferentiated culture.

The nitrogen plays an important role in homeostasis of plants and, therefore, determines the growth, development, and yielding. Plants can utilize mineral form of nitrogen as a nitrate $\left(\mathrm{NO}_{3}{ }^{-}\right)$and ammonium $\left(\mathrm{NH}_{4}{ }^{+}\right)$. Natural growth conditions determined the relative proportion of both forms depending on oxygenation, acidity, and humidity of the soil. Their assimilation can be realized by active transport carried out by specialized transporters; also ammonium ions can passively migrate through ion channels, as well (Taylor and Bloom 1998). Nitrate after uptake by plant roots may be reduced to ammonium and subsequently to amino acids, or be transported to leafs, accumulate in vacuole or is removed to the apoplast. Consumption of reduced form of nitrogen $\left(\mathrm{NH}_{4}{ }^{+}\right)$requires less energy than oxygenated $\left(\mathrm{NO}_{3}{ }^{-}\right)$form, but the assimilation of ammonium generates additional energetic costs associated with the supply of ketoacids from aerial parts (Bloom et al. 1992). In addition, for most cultivated and growing wild plants, using ammonium is toxic when used as a sole source of nitrogen (Britto and Kronzucker 2002). This phenomenon still needs an unequivocal explanation: one undeniable seems to be the $\mathrm{pH}$ influence. Both mineral forms adsorption which is associated with changes in $\mathrm{pH}$ of the rhizosphere: ammonium uptake decreases, while nitrate increases $\mathrm{pH}$. Nitrogen can be additionally uptaken in form of organic compound, mainly as a mixture of amino acids. The availability of amino acids in the soil depends on proteolysis and the buffer capacity of the rhizosphere: distribution of individual amino acids is affected by their charge. Second important requirement determines the relationship between amino acids concentration and mediating transporters in the root plasmalemma (Näsholm et al. 2009).

In plant cell cultures, the nitrogen source may significantly affect the plant cell proliferation, root growth, and metabolite production (Cui et al. 2010; Zhang et al. 2011). Nitrate had a clear influence on the alkaloid content and on the atropine/scopolamine ratio in hairy root culture of Atropa belladonna (Bensaddek et al. 2001; Chashmi et al. 2008). Reduced level of ammonium combined with increased level of nitrate favors the production of triterpenoids: gymnaemic acid in Gymnema sylvestre (Praveen 2011) and withanolide A in Withania somnifera (Praveen 2013), while the elimination of nitrate from the media of Chrysanthemum cinerariaefolium culture induced twofold increase in accumulation of pyrethrin (Rajashekaran et al. 1991). However, all the aforementioned effects of the culture medium modifications differ among the species, lines, and type of cultures (Aoki et al. 1997).

In our study, the nitrate and ammonium concentrations of $1 / 2$ MS medium were modified. Their effects on the growth, production of oleanolic acid glycosides, as well as their secretion into the medium were investigated. The suspension cultures originated from different explants and three lines of hairy roots were compared to bring out general tendencies for marigold.

\section{Materials and methods}

\section{Plant material}

Mature embryos of the marigold Calendula officinalis cv. Persimmon Beauty were excised from seeds and sterilized for 20 min with a commercial hypochlorite agent "Domestos" (Unilever) diluted with water (1:3, v/v). Subsequently, the embryos were rinsed three times in sterile liquid $1 / 2$ MS medium (Murashige and Skoog 1962). Sterilized embryos were germinated on solid $1 / 2$ MS in $\varnothing 10 \mathrm{~cm}$ Petri dish.

Suspension cultures (SC) of marigold were initiated from apical buds (B), cotyledons (C), hypocotyls $(\mathrm{H})$, and 
embryo roots (R) dissected from sterile 7-8-day-old seedlings. Explants were introduced into modified liquid 1/2 MS medium (MS4) supplemented with $1 \mathrm{mg} \mathrm{L}^{-1}$ of 2.4-D: buds and roots immediately, cotyledons, and hypocotyls after cutting on thin slices.

Hairy roots cultures (HR) of marigold were initiated according to the procedure described earlier (Długosz et al. 2013). Lines selected for current topics were: CC16, derived from cotyledons, after 36 and 72 subcultures; MC3, derived from cotyledons, containing the $\beta$-glucuronidase $(G U S)$ reporter gene under the control of promoter (1058 bp upstream region from the ATG codon) of tomato NIK (Nematode-Induced Kinase) gene (DFCI Tomato Gene Index TC218759) (Święcicka et al. 2009), after 36 subcultures; $\mathrm{CH} 2$, derived from hypocotyls, after 72 subcultures.

\section{Maintenance of the cultures}

Established SC were subcultured every 2 weeks by transfer of 3-mL packed cell volume (PCV) tissue to 100-mL Erlenmeyer flask containing $50 \mathrm{~mL}$ of liquid medium. Established lines of HR were subcultured every 3-4 weeks by transfer of one piece cut of from young root to 50-mL Erlenmeyer flask with $25 \mathrm{~mL}$ of fresh medium. All types of cultures were maintained in complete darkness at $24{ }^{\circ} \mathrm{C}$ and shaken at $120 \mathrm{rpm}$. For OA content determination, SC and HR were transferred to 250-mL Erlenmeyer flasks containing $100 \mathrm{~mL}$ of liquid 1/2 MS medium (Table 1): $6 \mathrm{~mL}$ of PCV for SC and 1-2 fragments of incremental young tissue for $\mathrm{HR}$, respectively, and were cultured for 14 (SC) or 30 (HR) days. Growth of SC was calculated as a percent of relative growth during a 14-day period which was calculated according to formula: $\left[\left(\mathrm{FW}_{\mathrm{F}}-\mathrm{FW}_{\mathrm{I}}\right) / \mathrm{FW}_{\mathrm{I}}\right] \times 100$ (where: $\mathrm{FW}_{\mathrm{F}}-$ final fresh weight, $\mathrm{FW}_{\mathrm{I}}$-initial fresh weight). Appropriate capacities of inoculum were weighted at the beginning of the culture, and the final fresh weight was measured after the liquid filtration.

Table 1 Composition of $1 / 2$ MS media based on Murashige and Skoog (1962) used for suspension cultures and hairy root lines maintenance

\begin{tabular}{lllr}
\hline Design of medium & \multicolumn{3}{l}{ Components $\left(\mathrm{mg} \mathrm{L}^{-1}\right)$} \\
\cline { 2 - 4 } & $\mathrm{NH}_{4} \mathrm{NO}_{3}$ & $\mathrm{KNO}_{3}$ & Edamine \\
\hline MS1 ${ }^{\mathrm{RC}}$ & 825 & 950 & 250 \\
MS2 & 825 & 950 & 2500 \\
MS3 & - & 2380 & 250 \\
MS4 & - & 2380 & 2500 \\
MS5 & 1400 & - & 250 \\
MS6 & 1400 & - & 2500 \\
\hline
\end{tabular}

Half-strength of macro-elements with a full set of micro-elements and organic components, edamine-peptone from lactalbumin; sucrose $30 \mathrm{mg} \mathrm{L}^{-1}$, media for SC contained $1 \mathrm{mg} \mathrm{L}^{-1}$ of 2.4-D, RC media for regenerative capacity: sucrose $10 \mathrm{mg} \mathrm{L}^{-1}$
Regenerative capacity of established culture was verified through the transfer of cell aggregates (inoculum size 1/4-1/8-mL PCV $100 \mathrm{~mL}^{-1}$ medium) from proliferation media (MS1-6) to medium without growth regulators $\left(\mathrm{MS}^{\mathrm{RC}}\right)$ under fluorescent illumination $\left(54 \mu \mathrm{mol} \mathrm{m} \mathrm{m}^{2} \mathrm{~s}^{-1}\right)$, with 16/8-h photoperiod.

\section{Nitrogen source modification}

The effect of nitrogen source on tissue growth and saponin production in SC and HR was estimated by changes in the concentration of ammonium and potassium nitrate in basal $1 / 2$ MS medium, which contained 825 and $950 \mathrm{mg} \mathrm{L}^{-1}$, respectively. Second step was evaluation of the effect of rising concentration of potassium nitrate with ammonium omission. Proposed concentrations were 1-, 2.5-, 3.5-, and 4.5times higher than in standard $1 / 2 \mathrm{MS}$. The final issue was to determine the impact of altering the ammonium:nitrate ratio for HR culture. Media supplemented with appropriate $\mathrm{KNO}_{3}$ and $\mathrm{NH}_{4} \mathrm{NO}_{3}$ quantities of $5: 1 ; 4: 2 ; 3: 3$ of $\mathrm{NO}_{3}{ }^{-} / \mathrm{NH}_{4}{ }^{+}$ratio were added (to keep nitrogen level constant $-60 \mathrm{mM}$, which was the level equal with a full salt strength MS medium).

\section{Extraction of oleanolic acid}

Cells and roots after drying in room temperature were ground with methanol and boiled under reflux for $60 \mathrm{~min}$, the culture medium was extracted three times with $20 \mathrm{~mL}$ of 1-butanol. The extracts were evaporated under reduced pressure and subsequently hydrolyzed with $10 \% \mathrm{HCl}$ in methanol. The hydrolysate diluted with two parts of water were extracted three times with $20 \mathrm{~mL}$ of diethyl ether and separated by thin-layer chromatography (TLC). Purified OA was methylated with an ether solution of diazomethane (Janiszowska and Kasprzyk 1977). Detailed description of the extraction procedure was published previously by Wiktorowska et al. (2010) and Długosz et al. (2013).

\section{Quantification of oleanolic acid}

Quantitative measurement of OA was performed by gas-liquid chromatography (GLC) at $270{ }^{\circ} \mathrm{C}$ on a Shimadzu GC-2014 instrument equipped with a flame ionization detector (FID). Samples were applied by split injection $1: 5$ on a ZB-1 $30 \mathrm{~m} \times 0.25 \mathrm{~mm} \times 0.25 \mu \mathrm{m}$ column (Phenomenex). The temperature of the injector and detector was $290{ }^{\circ} \mathrm{C}$. Nitrogen was used as the carrier gas at a flow rate of $1.2 \mathrm{~mL} \mathrm{~min}^{-1}$. Peak identification (Fig. 1) and quantification of oleanolic acid were carried out by referring to a calibration curve prepared with an authenticated sample of methylated oleanolic acid as the standard (Długosz et al. 2013). In addition, the methyl ester of OA was identified by GLC-MS on an Agilent Technologies 7890A gas chromatograph 


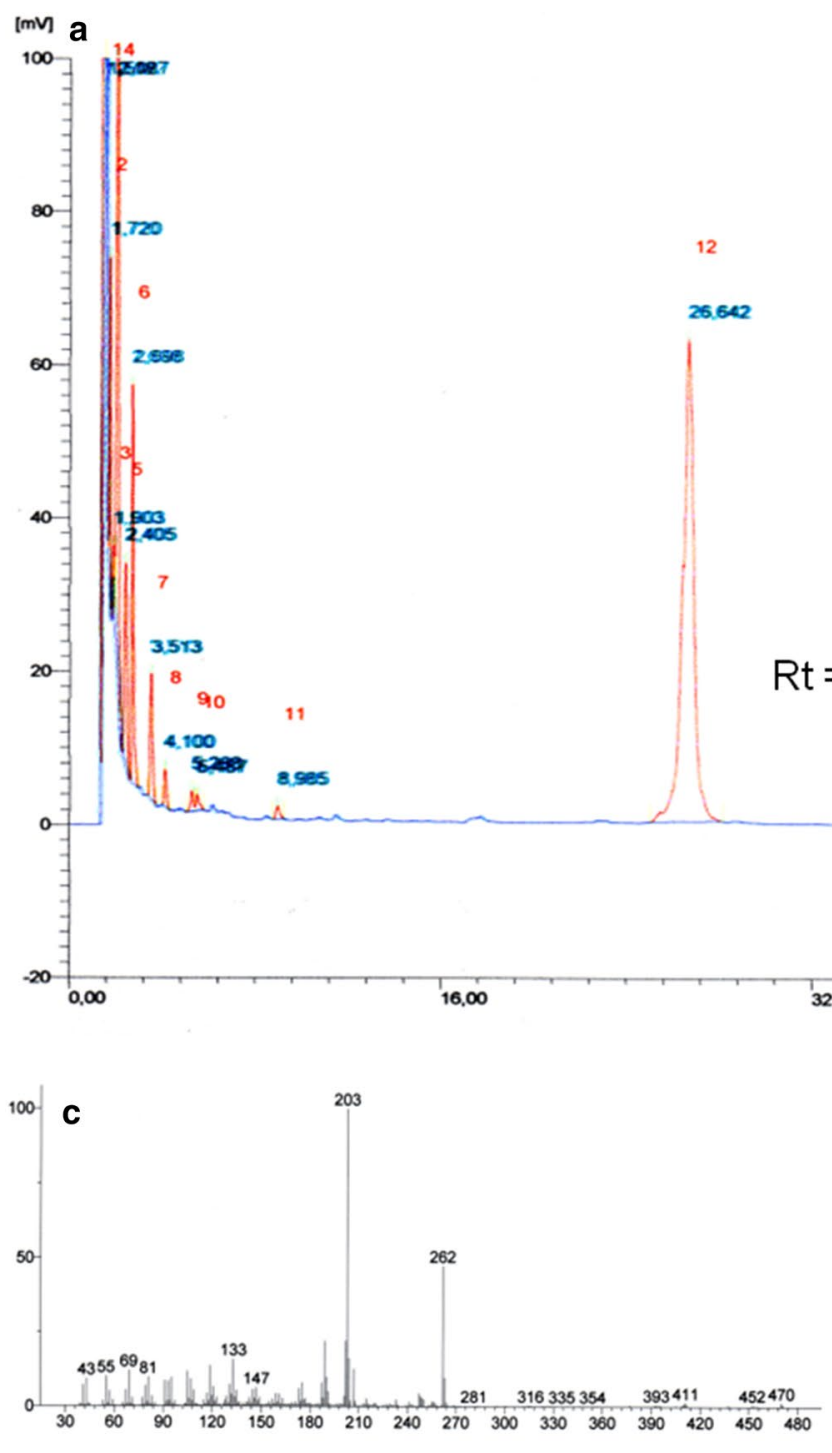

\section{b}

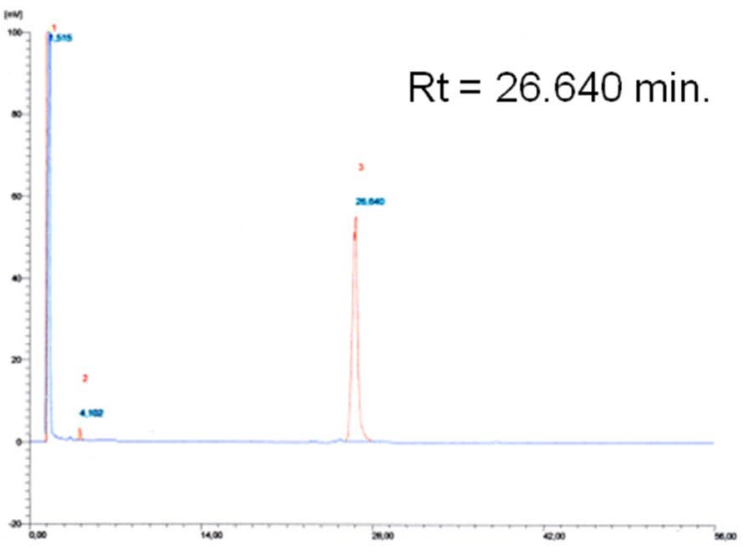

$\mathrm{Rt}=26.642 \mathrm{~min}$.

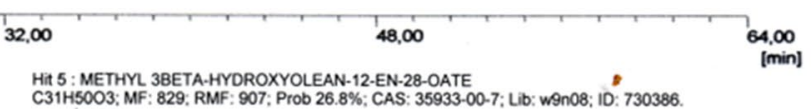

C31H5003; MF: 829: RMF: 907; Prob 26.8\%; CAS: 35933-00-7; Lib: w9n08: ID: 730386.

203

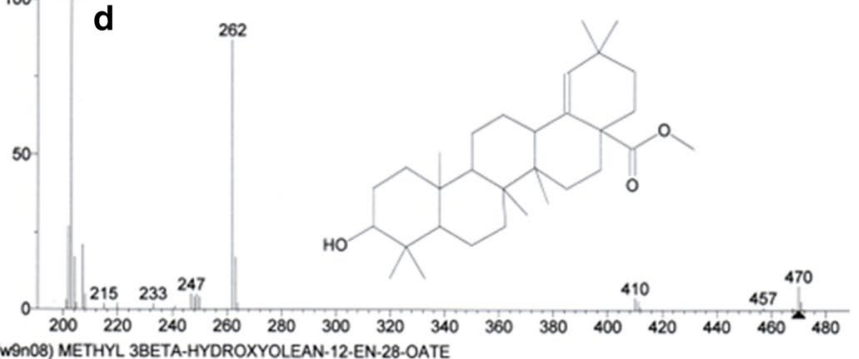

Fig. 1 Oleanolic acid identification in suspension and hairy root cultures of $C$. officinalis. a GLC chromatogram of OA (methyl ester derivative) isolated from $\mathrm{CH} 2$ tissue of $\mathrm{HR}$ after cultivation in MS2 liquid medium. $\mathbf{b}$ GLC chromatogram of authentic standard of methyl

ester of OA. c GLC-MS of OA (methyl ester derivative) isolated from $\mathrm{CH} 2$ tissue of $\mathrm{HR}$ after cultivation in MS2 liquid medium. d GLC-MS of standard of methyl ester of OA

coupled with a 5975C mass spectrometric detector. Samples (dissolved in 1-4 $\mu \mathrm{L}$ of a 5:1 diethyl ether:methanol mixture, v:v) were applied by split injection 1:10 on an HP-5MS $30 \mathrm{~m} \times 0.25 \mathrm{~mm}, 0.25-\mu \mathrm{m}$ column (Agilent Technologies). Helium was used as the carrier gas at a flow rate of $1 \mathrm{~mL} \mathrm{~min}{ }^{-1}$. The following parameters were employed: column temp. $280{ }^{\circ} \mathrm{C}$, inlet and flame ionization detector (FID) temp. $290{ }^{\circ} \mathrm{C}$, MS transfer line temp. $275^{\circ} \mathrm{C}$, quadrupole temp. $150{ }^{\circ} \mathrm{C}$, ion source temp. $230{ }^{\circ} \mathrm{C}$, EI $70 \mathrm{eV}$, $\mathrm{m} / \mathrm{z}$ range 33-500; FID gas ( $\mathrm{H} 2$ from a hydrogen generator) flow $30 \mathrm{~mL} \mathrm{~min}^{-1}$, air flow $400 \mathrm{~mL} \mathrm{~min}^{-1}$. Identification was made by comparing the mass spectra with library data from Wiley 9th Ed. and NIST 2008 Lib. SW (version 2010) and,

where available, by comparison of retention times and corresponding mass spectra with those of authentic standards.

\section{Results}

\section{Suspension culture: growth and saponin content}

Suspension cultures of marigold were induced from all tested explants. First reaction was observed after 2 weeks. Embryo-like structures appeared the earliest on the surface of apical buds, then on the hypocotyls and finally on the roots. Sliced cotyledons responded at the latest. 

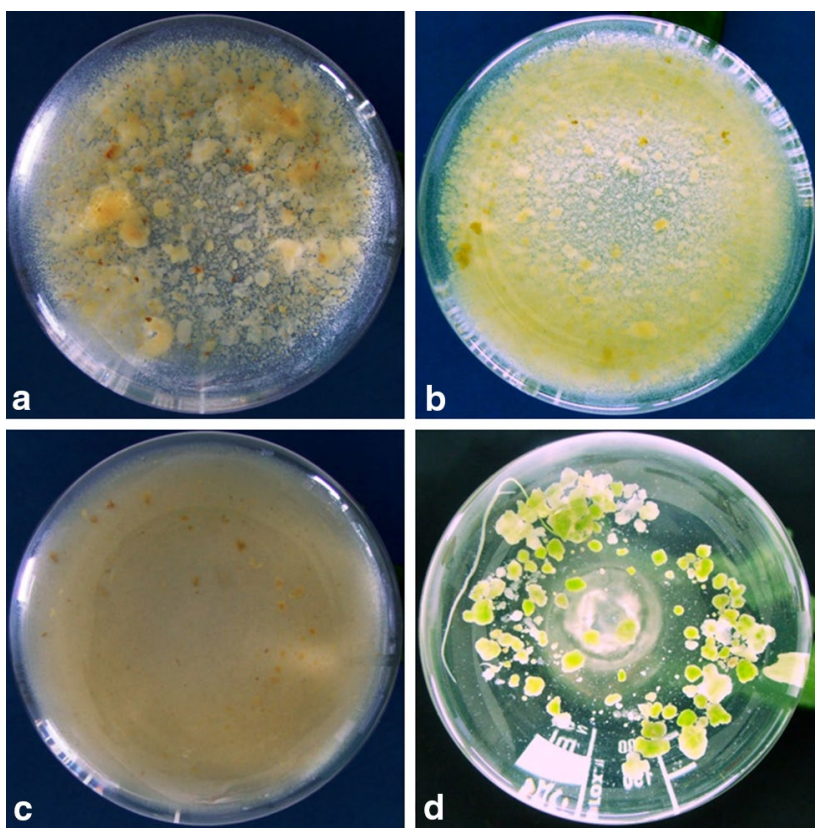

Fig. 2 Proliferation and differentiation of SC C. officinalis. a Aggregates of embryo-like structures proliferating in MS3 medium, culture derived from root (R) after 3 months from initiation. b Culture of organogenic callus without advancing embryo stages in MS4 medium, culture derived from hypocotyl $(\mathrm{H})$. c Different morphology of cotyledon culture (C): small aggregate size in media with standard edamine concentration (MS4). d Direct organogenesis: aggregate of embryo-like structures after 4-weeks in medium without 2.4-D, inoculum derived from $\mathrm{R}$ culture proliferated in MS3

Established SC were achieved after 3 months. During the first 2-6 months, the culture consisted of globular structures resembles early stages of somatic embryos which were showing single or in cluster proliferation (Fig. 2a). Afterwards, this globular structures were replaced by organogenic callus without advancing embryo stages (Fig. 2b), which periodically changed their morphology to small-aggregated (Fig. 2c). Similar tendency was found in established culture regardless of the origin. Different nitrogen forms influenced the diameter of aggregates. When organic form (edamine) predominated or proportion of mineral nitrogen as for $1 / 2$ MS was used, aggregates were smaller $(<1 \mathrm{~mm})$ than in the media with standard level of edamine and with unbalanced mineral nitrogen ratio (nitrate or ammonium form predominated). This effect was not observed for SC derived from cotyledon: small aggregate size was obtained in the medium with standard edamine concentration $\left(250 \mathrm{mg} \mathrm{L}^{-1}\right)$ and nitrate as a sole mineral source of nitrogen (Fig. 2c).

Next step was to measure effect of five different nitrogen source modifications to the $1 / 2$ MS medium (Table 1). After two subcultures with 4 week intervals, the third subculture provided the data for growth and glycosides concentration in the cells. The influence of the media composition on growth values $\mathrm{GV}(\%)$ of the culture originated from
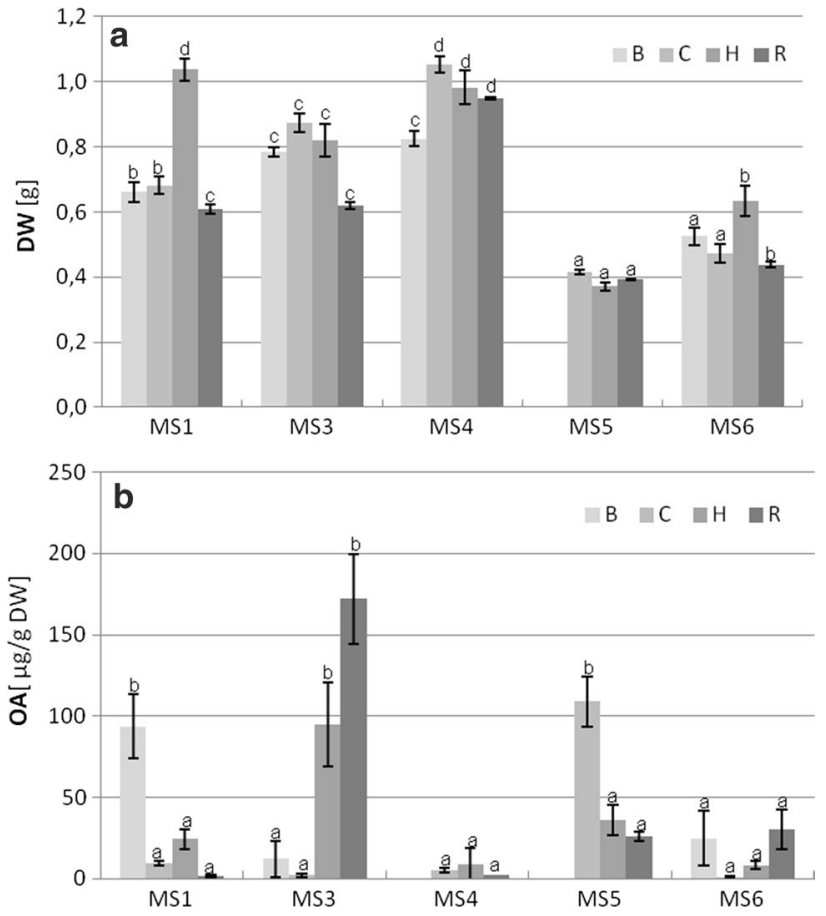

Fig. 3 Effects of media composition on growth (a) and OA accumulation (b) in suspension culture determined after 14 days of culture. Mean \pm standard error of three replicates. Means with common letters within the line are not significantly different at $P \leq 0.05$ according to Fisher's multiple range test

the four types of seedling explants is depicted on Fig. 3a. Suspension culture of marigold proliferated quickly in the media, in which they were initiated (MS4). In that medium, variant ammonium nitrate was eliminated, the content of potassium nitrate was increased 2.5 times, and content of edamine-peptone from lactalbumin-tenfold. GV (\%) of the fresh weight ranged from $393.50 \pm 17.66 \%$ for culture B originating from apical bud to $540.19 \pm 25.05 \%$ for culture $\mathrm{H}$ derived from hypocotyl. In general, all cultures were characterized by high growth rate if the nitrate was only source for mineral nitrogen. If both forms of mineral nitrogen were balanced as in the standard MS medium, fresh weight was decreased twice. Supplementation of the edamine at the tenfold concentration to the medium, in which nitrate was the only mineral form (MS3), improved cells proliferation by over $30 \%$ on average (MS4), but only for $\mathrm{C}$ and $\mathrm{H}$ culture, it was statistically significant. The same lactalbumin hydrolysate concentration with both mineral forms coexistence at almost 1:1 (MS5, MS6), resulted in statistically significant increase in the growth value over $94 \%$.

Regenerative capacity of established suspension culture was observed in the liquid medium MS1 ${ }^{\mathrm{SE}}$ (Table 1). After 4 weeks, expanding globular somatic embryos usually fused with clusters and chlorophyll appeared area was observed (Fig. 2d). Some of the aggregates were equipped with thin 
embryo roots. However, no properly developed cotyledons and typical bipolar structure were present. Tissue showed secondary proliferation after removing it to the regeneration medium. Such embryo-like structures placed on the surface of solid medium were enveloped with callus which hampered their growth and differentiation (data not presented).

Crucial for initiation cultures able for saponins accumulation was root, apical bud, and hypocotyl explants; however, the composition of the medium was not insignificant. The highest OA glycosides concentration in culture cells originated from the root was present when cultivated in MS3 media: $171.97 \pm 27.62 \mu \mathrm{g} \mathrm{g}^{-1}$ DW (Fig. $3 b$ ). The SC originated from other two explants accumulated saponins at ca. $74 \%$ lower concentration. Media supplemented with modified ratio of both mineral forms of nitrogen (1:1) - MS5reduced the growth rate and saponin content except the $\mathrm{C}$ culture, for which such conditions created the compromise between culture growth and metabolite production. The results demonstrated for the SC show that there was no correlation between saponin content and biomass (FW or DW). Organic nitrogen source, represented here by peptone from lactalbumin at tenfold higher concentration, decidedly inhibited the synthesis of oleanolic acid glycosides. For the B culture so efficiently, that these compounds were completely absent in their cells. Supplementation with peptone accelerated the SC induction, as in the initial medium (MS4) which contains tryptophan - the auxin precursor-which interacts with nitrate and 2.4-D to enhance embryogenic capacity of the explants.

\section{Hairy roots: growth, saponin content in tissue, and release into the media}

The hairy root lines chosen for nitrogen feeding optimization were selected due to stable and fast growth in liquid media and efficient saponins production. In the first experiment, our objective was the comparison of growth and saponins concentration in hairy roots with suspension culture. Media used for cultivation were composed similarly, with exception of presence of plant growth regulators, and additional variant: standard medium ( $1 / 2 \mathrm{MS})$ supplemented with high edamine content (MS2). Oleanolic acid glycosides, which were secreted to the medium, were determined after cultivation time. Lines selected to this task were two of control lines: $\mathrm{CC} 16$ (after 36 subcultures) and $\mathrm{CH} 2$ (after 72 subcultures) and one modified-MC3 (after 36 subcultures) maintained in standard $1 / 2$ MS medium. The growth of hairy roots culture measured in form of a dry weight (Fig. 4) was genotype-dependent: control lines $(\mathrm{C})$ achieved the higher DW than modified line (M) under any proposed culture medium. In general, hairy roots of marigold had a better growth in standard $1 / 2$ MS media (MS1) or modified by elimination of ammonium and increased concentration of

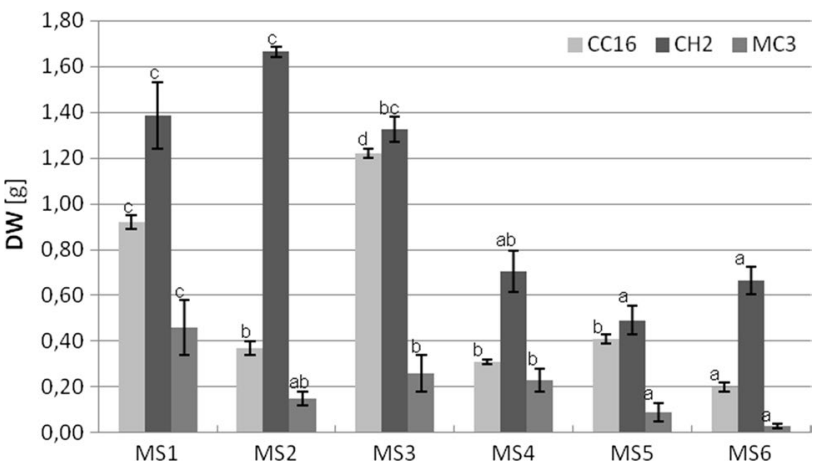

Fig. 4 Effects of medium composition on hairy root lines growth in liquid medium. Values are mean \pm SE of three replications. Means with common letters within the lines are not significantly different at $P \leq 0.05$ according to Fisher's multiple range test
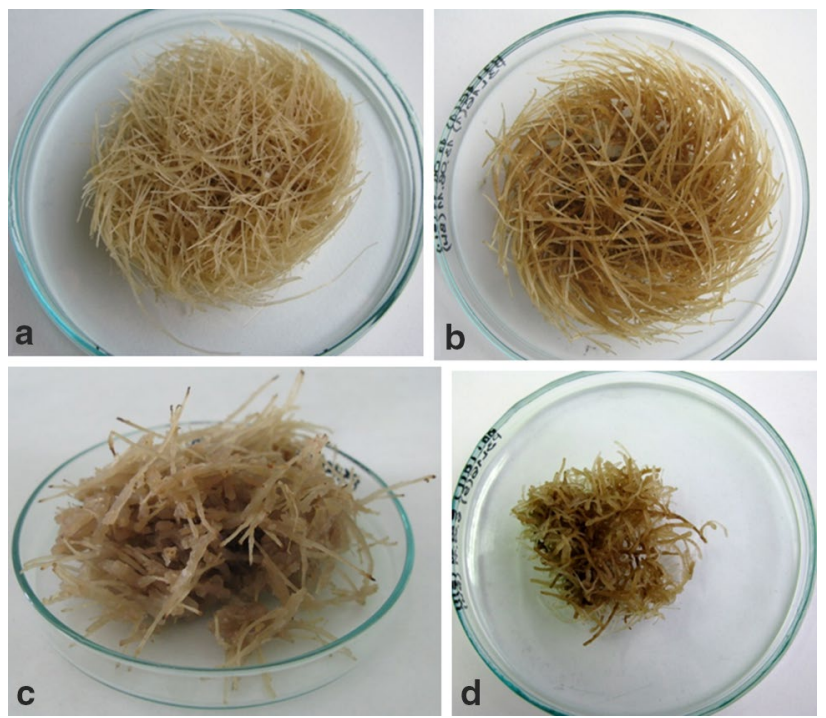

Fig. 5 Response to nitrogen source of $C$. officinalis hairy roots after 30-day growth in liquid medium: a typical morphology of HR in control media; MS1 line CC16, b ammonium elimination favors saponin accumulation and thicker roots in diameter; line CC16 in MS3, c increased peptone supplementation generates callusing; line $\mathrm{CH} 2$ in MS2, $\mathbf{d}$ or inhibited growth and necrosis; line CC16 in MS4

nitrate (MS3). Tissue after 30-day growth in such media was in good condition: they were free of necrosis and callus formation (Fig. 5a), while in MS3, they had slightly darker colour (Fig. 5b). Media supplemented with high content of organic source of nitrogen (MS2, MS4, and MS6)-peptone, lactalbumin hydrolysate - in contrast to the $\mathrm{SC}$ - decreased the growth rate. However, line $\mathrm{CH} 2$ showed that adding peptone over standard level improved the biomass accumulation in the media with balanced ammonium/nitrate ions ratio like in $1 / 2$ MS (MS2), as well as in media with equimolar concentration of both mineral forms (MS6). Depending on the line, after growth in high edamine concentration, tissue 
Table 2 Biomass and contents of OA glycosides in suspension and hairy root cultures of $C$. officinalis from 0.3-L shake flask

\begin{tabular}{|c|c|c|c|c|c|c|c|}
\hline \multirow[t]{2}{*}{ Culture type } & \multirow[t]{2}{*}{ Line } & \multirow[t]{2}{*}{ Medium } & \multicolumn{3}{|l|}{ Biomass } & \multicolumn{2}{|l|}{ OA content } \\
\hline & & & $\mathrm{DW}(\mathrm{g})$ & $\mathrm{FW}(\mathrm{g})$ & DW $(\%)$ & $\overline{\mathrm{DW}(\%)}$ & Production $\left(\mathrm{mg} \mathrm{flask}^{-1}\right)$ \\
\hline \multirow[t]{20}{*}{ SC } & \multirow[t]{5}{*}{$\mathrm{B}$} & MS1 & $0.66 \pm 0.03 b$ & $12.30 \pm 1.03 b$ & $5.41 \pm 0.20 \mathrm{a}$ & $0.0094 \pm 0.0020 \mathrm{~b}$ & $0.062 \pm 0.002 b$ \\
\hline & & MS3 & $0.79 \pm 0.01 \mathrm{c}$ & $13.15 \pm 2.74 b$ & $5.28 \pm 0.84 a$ & $0.0012 \pm 0.0011 \mathrm{a}$ & $0.010 \pm 0.008 \mathrm{a}$ \\
\hline & & MS4 & $0.83 \pm 0.02 c$ & $14.43 \pm 0.82 b$ & $5.73 \pm 0.18 \mathrm{a}$ & 0.0000 & 0.000 \\
\hline & & MS5 & nd & nd & nd & nd & nd \\
\hline & & MS6 & $0.53 \pm 0.03 a$ & $7.69 \pm 0.13 a$ & $6.85 \pm 0.42 b$ & $0.0025 \pm 0.0017 \mathrm{a}$ & $0.013 \pm 0.008 \mathrm{a}$ \\
\hline & \multirow[t]{5}{*}{$\mathrm{C}$} & MS1 & $0.68 \pm 0.03 b$ & $11.70 \pm 0.83 b$ & $5.86 \pm 0.31 b$ & $0.0009 \pm 0.0001 \mathrm{a}$ & $0.006 \pm 0.001 \mathrm{a}$ \\
\hline & & MS3 & $0.87 \pm 0.03 c$ & $15.36 \pm 0.63 c$ & $5.69 \pm 0.06 \mathrm{ab}$ & $0.0002 \pm 0.0001 \mathrm{a}$ & $0.002 \pm 0.001 \mathrm{a}$ \\
\hline & & MS4 & $1.05 \pm 0.03 \mathrm{~d}$ & $19.74 \pm 0.46 \mathrm{~d}$ & $5.33 \pm 0.03 a$ & $0.0005 \pm 0.0002 \mathrm{a}$ & $0.006 \pm 0.001 \mathrm{a}$ \\
\hline & & MS5 & $0.42 \pm 0.01 \mathrm{a}$ & $7.48 \pm 0.45 a$ & $5.58 \pm 0.23 \mathrm{ab}$ & $0.0109 \pm 0.0015 b$ & $0.045 \pm 0.003 b$ \\
\hline & & MS6 & $0.47 \pm 0.03 a$ & $6.80 \pm 0.45 a$ & $6.94 \pm 0.05 c$ & $0.0001 \pm 0.0001 \mathrm{a}$ & $0.001 \pm 0.001 \mathrm{a}$ \\
\hline & \multirow[t]{5}{*}{$\mathrm{H}$} & MS1 & $1.04 \pm 0.03 \mathrm{~d}$ & $20.46 \pm 0.26 \mathrm{~d}$ & $5.08 \pm 0.23 \mathrm{ab}$ & $0.0024 \pm 0.0006 \mathrm{a}$ & $0.025 \pm 0.006 \mathrm{a}$ \\
\hline & & MS3 & $0.82 \pm 0.05 c$ & $14.88 \pm 0.97 \mathrm{c}$ & $5.52 \pm 0.10 b$ & $0.0095 \pm 0.0025 b$ & $0.078 \pm 0.026 b$ \\
\hline & & MS4 & $0.98 \pm 0.05 d$ & $19.94 \pm 1.57 \mathrm{~d}$ & $4.95 \pm 0.14 \mathrm{a}$ & $0.0009 \pm 0.0009 a$ & $0.009 \pm 0.001 \mathrm{a}$ \\
\hline & & MS5 & $0.37 \pm 0.01 \mathrm{a}$ & $6.70 \pm 0.46 \mathrm{a}$ & $5.57 \pm 0.34 b$ & $0.0036 \pm 0.0009 a$ & $0.013 \pm 0.003 a$ \\
\hline & & MS6 & $0.64 \pm 0.05 b$ & $9.62 \pm 0.90 b$ & $6.62 \pm 0.12 c$ & $0.0008 \pm 0.0002 \mathrm{a}$ & $0.007 \pm 0.002 \mathrm{a}$ \\
\hline & \multirow[t]{5}{*}{$\mathrm{R}$} & MS1 & $0.61 \pm 0.02 \mathrm{c}$ & $11.69 \pm 0.24 c$ & $5.22 \pm 0.22 \mathrm{c}$ & $0.0002 \pm 0.0001 \mathrm{a}$ & $0.001 \pm 0.001 \mathrm{a}$ \\
\hline & & MS3 & $0.62 \pm 0.01 \mathrm{c}$ & $16.42 \pm 0.29 d$ & $3.78 \pm 0.00 \mathrm{a}$ & $0.0172 \pm 0.0027 b$ & $0.107 \pm 0.017 b$ \\
\hline & & MS4 & $0.95 \pm 0.01 \mathrm{~d}$ & $20.08 \pm 0.41 \mathrm{e}$ & $4.73 \pm 0.11 b$ & $0.0002 \pm 0.0001 \mathrm{a}$ & $0.002 \pm 0.001 \mathrm{a}$ \\
\hline & & MS5 & $0.39 \pm 0.01 \mathrm{a}$ & $5.56 \pm 0.05 \mathrm{a}$ & $7.06 \pm 0.10 \mathrm{e}$ & $0.0026 \pm 0.0003 a$ & $0.010 \pm 0.001 \mathrm{a}$ \\
\hline & & MS6 & $0.44 \pm 0.01 b$ & $7.26 \pm 0.17 b$ & $6.03 \pm 0.13 d$ & $0.0030 \pm 0.0013 \mathrm{a}$ & $0.013 \pm 0.008 \mathrm{a}$ \\
\hline \multirow[t]{18}{*}{ HR } & \multirow[t]{6}{*}{$\mathrm{CC} 16$} & $\operatorname{MS1}(\mathrm{C})$ & $0.92 \pm 0.03 c$ & $11.88 \pm 0.19 \mathrm{e}$ & $8.14 \pm 0.15 b$ & $1.5600 \pm 0.0150 b$ & $17.932 \pm 3.880 \mathrm{c}$ \\
\hline & & MS2 & $0.37 \pm 0.03 b$ & $4.70 \pm 0.67 b$ & $9.24 \pm 0.05 c$ & $1.9040 \pm 0.1510 b$ & $8.908 \pm 1.407 \mathrm{~b}$ \\
\hline & & MS3 & $1.22 \pm 0.02 \mathrm{~d}$ & $9.82 \pm 0.13 \mathrm{~d}$ & $12.22 \pm 0.23 \mathrm{~d}$ & $5.9610 \pm 0.1040 c$ & $73.943 \pm 3.680 \mathrm{~d}$ \\
\hline & & MS4 & $0.31 \pm 0.01 b$ & $2.39 \pm 0.05 \mathrm{ab}$ & $12.88 \pm 0.79 \mathrm{~d}$ & $5.7810 \pm 0.3860 c$ & $19.865 \pm 3.813 \mathrm{c}$ \\
\hline & & MS5 & $0.41 \pm 0.02 b$ & $6.19 \pm 0.09 c$ & $6.90 \pm 0.18 \mathrm{a}$ & $0.5290 \pm 0.1200 \mathrm{a}$ & $3.830 \pm 0.904 \mathrm{a}$ \\
\hline & & MS6 & $0.20 \pm 0.02 \mathrm{a}$ & $2.29 \pm 0.07 \mathrm{a}$ & $9.59 \pm 0.04 c$ & $0.4580 \pm 0.0240 \mathrm{a}$ & $1.172 \pm 0.007 \mathrm{a}$ \\
\hline & \multirow[t]{6}{*}{$\mathrm{CH} 2$} & $\operatorname{MS1}(\mathrm{C})$ & $1.39 \pm 0.14 \mathrm{c}$ & $17.03 \pm 1.34 b$ & $7.27 \pm 0.12 b$ & $0.4340 \pm 0.0768 b$ & $5.164 \pm 0.373 b$ \\
\hline & & MS2 & $1.67 \pm 0.02 \mathrm{c}$ & $23.80 \pm 1.62 b$ & $7.58 \pm 0.42 b$ & $0.3240 \pm 0.0144 b$ & $5.445 \pm 0.420 b$ \\
\hline & & MS3 & $1.33 \pm 0.05 b c$ & $9.21 \pm 0.87 \mathrm{a}$ & $13.69 \pm 0.34 \mathrm{e}$ & $1.0890 \pm 0.1310 \mathrm{~d}$ & $14.502 \pm 1.263 \mathrm{c}$ \\
\hline & & MS4 & $0.70 \pm 0.09 \mathrm{ab}$ & $6.85 \pm 0.53 a$ & $12.39 \pm 0.29 \mathrm{~d}$ & $0.6330 \pm 0.1556 b$ & $6.490 \pm 1.560 b$ \\
\hline & & MS5 & $0.49 \pm 0.06 \mathrm{a}$ & $7.30 \pm 0.71 \mathrm{a}$ & $6.49 \pm 0.26 \mathrm{a}$ & $0.1750 \pm 0.0330 \mathrm{a}$ & $0.889 \pm 0.078 \mathrm{a}$ \\
\hline & & MS6 & $0.67 \pm 0.06 \mathrm{a}$ & $7.15 \pm 0.74 a$ & $9.34 \pm 0.21 \mathrm{c}$ & $0.1610 \pm 0.0143 \mathrm{a}$ & $1.072 \pm 0.075 \mathrm{a}$ \\
\hline & \multirow[t]{6}{*}{ MC3 } & $\operatorname{MS1(C)}$ & $0.46 \pm 0.12 \mathrm{c}$ & $3.52 \pm 0.68 \mathrm{c}$ & $12.98 \pm 0.95 \mathrm{ab}$ & $0.7020 \pm 0.2160 \mathrm{a}$ & $3.470 \pm 1.839 \mathrm{a}$ \\
\hline & & MS2 & $0.15 \pm 0.03 \mathrm{ab}$ & $1.16 \pm 0.23 \mathrm{ab}$ & $13.48 \pm 0.31 \mathrm{abc}$ & $0.9550 \pm 0.1830 \mathrm{a}$ & $4.096 \pm 0.350 \mathrm{a}$ \\
\hline & & MS3 & $0.26 \pm 0.08 b$ & $1.38 \pm 0.52 b$ & $18.34 \pm 1.02 \mathrm{~d}$ & $3.4890 \pm 0.1370 b$ & $6.921 \pm 1.324 b$ \\
\hline & & MS4 & $0.23 \pm 0.05 b$ & $1.61 \pm 0.34 b$ & $14.28 \pm 0.26 c$ & $3.5730 \pm 0.1070 b$ & $9.799 \pm 0.840 \mathrm{~b}$ \\
\hline & & MS5 & $0.09 \pm 0.04 \mathrm{a}$ & $0.68 \pm 0.38 \mathrm{ab}$ & $12.42 \pm 0.53 a$ & $0.7900 \pm 0.1090 \mathrm{a}$ & $1.454 \pm 0.221 \mathrm{a}$ \\
\hline & & MS6 & $0.03 \pm 0.01 \mathrm{a}$ & $0.24 \pm 0.04 a$ & $13.75 \pm 0.33 b c$ & $0.8410 \pm 0.0580 \mathrm{a}$ & $0.369 \pm 0.044 \mathrm{a}$ \\
\hline
\end{tabular}


Table 2 (continued)

\begin{tabular}{|c|c|c|c|c|c|c|c|}
\hline \multirow[t]{2}{*}{ Culture type } & \multirow[t]{2}{*}{ Line } & \multirow[t]{2}{*}{ Medium } & \multicolumn{3}{|l|}{ Biomass } & \multicolumn{2}{|l|}{ OA content } \\
\hline & & & DW (g) & FW (g) & DW (\%) & DW (\%) & Production $\left(\mathrm{mg} \mathrm{flask}^{-1}\right)$ \\
\hline \multirow[t]{18}{*}{ HR } & \multirow[t]{9}{*}{$\mathrm{CC} 16$} & $1 / 2 \mathrm{MS}(\mathrm{C} 1)$ & $0.78 \pm 0.03 a$ & $10.11 \pm 0.17 \mathrm{c}$ & $7.76 \pm 0.16 a$ & $0.2120 \pm 0.0229 a$ & $1.693 \pm 0.194 a$ \\
\hline & & $1 \times \mathrm{NO}_{3}$ & $1.10 \pm 0.04 \mathrm{c}$ & $8.04 \pm 0.63 \mathrm{ab}$ & $14.36 \pm 0.08 \mathrm{~d}$ & $0.6716 \pm 0.0246 c$ & $7.419 \pm 0.493 c$ \\
\hline & & $2.5 \times \mathrm{NO}_{3}$ & $0.91 \pm 0.03 b$ & $7.25 \pm 0.63 \mathrm{ab}$ & $11.66 \pm 0.26 \mathrm{c}$ & $0.4093 \pm 0.0563 b$ & $3.827 \pm 0.699 b$ \\
\hline & & $3.5 \times \mathrm{NO}_{3}$ & $1.07 \pm 0.02 \mathrm{c}$ & $8.35 \pm 0.56 b$ & $11.70 \pm 0.45 c$ & $0.5071 \pm 0.0567 b$ & $5.448 \pm 0.413 b$ \\
\hline & & $4.5 \times \mathrm{NO}_{3}$ & $0.71 \pm 0.06 \mathrm{a}$ & $6.52 \pm 0.78 a$ & $10.53 \pm 0.49 a$ & $0.2786 \pm 0.0772 \mathrm{a}$ & $2.092 \pm 0.764 \mathrm{a}$ \\
\hline & & $1 / 2 \mathrm{MS}(\mathrm{C} 2)$ & $0.78 \pm 0.03 b$ & $10.11 \pm 0.17 b$ & $7.76 \pm 0.16 b$ & $0.2120 \pm 0.0230 \mathrm{~b}$ & $1.693 \pm 0.194 \mathrm{a}$ \\
\hline & & $5 / 1$ & $1.06 \pm 0.00 \mathrm{c}$ & $11.77 \pm 0.2 \mathrm{c}$ & $8.94 \pm 0.10 \mathrm{c}$ & $0.4098 \pm 0.0054 d$ & $4.444 \pm 0.105 a$ \\
\hline & & $4 / 2$ & $1.25 \pm 0.27 \mathrm{c}$ & $9.67 \pm 0.34 b$ & $7.78 \pm 0.23 b$ & $0.3227 \pm 0.0448 \mathrm{c}$ & $2.288 \pm 0.157 \mathrm{a}$ \\
\hline & & $3 / 3$ & $0.45 \pm 0.02 \mathrm{a}$ & $6.85 \pm 0.13 a$ & $6.81 \pm 0.10 \mathrm{a}$ & $0.0994 \pm 0.0065 a$ & $0.464 \pm 0.050 \mathrm{a}$ \\
\hline & \multirow[t]{9}{*}{$\mathrm{CH} 2$} & $1 / 2 \mathrm{MS}(\mathrm{C} 1)$ & $1.00 \pm 0.07 b$ & $11.90 \pm 0.63 c$ & $8.85 \pm 0.14 \mathrm{a}$ & $0.4534 \pm 0.0120 \mathrm{~b}$ & $5.245 \pm 0.060 \mathrm{c}$ \\
\hline & & $1 \times \mathrm{NO}_{3}$ & $0.96 \pm 0.12 \mathrm{a}$ & $7.89 \pm 0.42 b$ & $11.37 \pm 1.35 b$ & $0.5389 \pm 0.0400 \mathrm{~b}$ & $4.176 \pm 0.080 \mathrm{c}$ \\
\hline & & $2.5 \times \mathrm{NO}_{3}$ & $0.75 \pm 0.08 \mathrm{a}$ & $6.41 \pm 0.85 \mathrm{ab}$ & $12.78 \pm 0.48 b$ & $0.6887 \pm 0.0691 \mathrm{c}$ & $5.789 \pm 0.393 c$ \\
\hline & & $3.5 \times \mathrm{NO}_{3}$ & $0.94 \pm 0.17 b$ & $7.47 \pm 0.97 \mathrm{ab}$ & $12.96 \pm 0.72 b$ & $0.8309 \pm 0.1210 \mathrm{~d}$ & $9.277 \pm 0.579 d$ \\
\hline & & $4.5 \times \mathrm{NO}_{3}$ & $0.83 \pm 0.08 \mathrm{a}$ & $5.85 \pm 0.70 \mathrm{a}$ & $13.21 \pm 0.21 b$ & $0.3201 \pm 0.1243 a$ & $2.471 \pm 0.241 \mathrm{a}$ \\
\hline & & $1 / 2 \mathrm{MS}(\mathrm{C} 2)$ & $0.93 \pm 0.07 \mathrm{c}$ & $10.89 \pm 0.51 c$ & $8.50 \pm 0.25 a$ & $0.4391 \pm 0.2018 b$ & $4.104 \pm 0.458 \mathrm{c}$ \\
\hline & & $5 / 1$ & $0.52 \pm 0.01 b$ & $6.34 \pm 0.23 b$ & $8.16 \pm 0.21 \mathrm{a}$ & $0.2066 \pm 0.1844 a$ & $1.068 \pm 0.090 \mathrm{a}$ \\
\hline & & $4 / 2$ & $0.56 \pm 0.04 b$ & $6.71 \pm 0.39 b$ & $8.29 \pm 0.17 a$ & $0.2519 \pm 0.0074 \mathrm{a}$ & $1.411 \pm 0.147 \mathrm{a}$ \\
\hline & & $3 / 3$ & $0.20 \pm 0.05 a$ & $1.91 \pm 0.62 \mathrm{a}$ & $10.62 \pm 0.86 b$ & $0.1970 \pm 0.0430 a$ & $0.363 \pm 0.034 a$ \\
\hline
\end{tabular}

The data for SC/HR were collected after 2 weeks/30 days of culture in a 300-mL Erlenmeyer flask containing 100-mL medium. Mean \pm standard error of three replicates; mean with common letters within the column is not significantly different at $P \leq 0.05$ according to Fisher's multiple range tests. Production for $\mathrm{SC}$ refers to cell accumulation for $\mathrm{HR}$ to tissue and media together

$\mathrm{Cl}$ control culture for $\mathrm{NO}_{3}{ }^{-}$modifications, $\mathrm{C} 2$ control culture for $\mathrm{NO}_{3}{ }^{-} / \mathrm{NH}_{4}{ }^{+}$ratio

was vitrified and embedded by callus (line $\mathrm{CH} 2$ : Fig. 5c) or showed inhibited growth and necrosis (line CC16: Fig. 5d). Content of DW (\%) in hairy roots was generally twofold higher than in suspension culture of marigold (Table 2). As we showed in our previous report (Długosz et al. 2013), the percent of DW in modified line (M) was higher than in control lines (C). In this work, the differences raised up to $66 \%$; in addition, the 2.5 times increased strength of nitrate (MS3) generated the highest content of DW (19.4\%).

Proposed set of $1 / 2$ MS modifications demonstrated strong impact of mineral and organic nitrogen source on oleanolic acid glycosides accumulation in hairy root cultures of marigold. Lines selected for evaluation varied in the origin, morphology, growth rate, and the saponin content. Figure 6 presents the accumulation of glycosides, expressed as an aglycone-oleanolic acid mass, in designed media after 30-day growth in shaken flasks. Elimination of the ammonium form (MS3) increased OA amount in tissue from 2.5 times for $\mathrm{CH} 2$ to 5 times for MC3 (Fig. 6a). Supplementation of nitrate with peptone from lactalbumin (MS4) generated a slight increase (MC3), slight decrease (CC16) and ca. $60 \%$ reduction $(\mathrm{CH} 2)$ of $\mathrm{OA}$. Medium where both mineral forms were equimolar (MS5) obtained OA concentration 2.5-3 times lower than for control culture, respectively, for $\mathrm{CH} 2$ and $\mathrm{CC} 16$ lines. Modified line (MC3) exceptionally accumulated OA in such conditions at ca. $1 \mathrm{mg} \mathrm{g}^{-1} \mathrm{DW}$ over control. This case was also interesting regarding secretion: saponins released to the medium had over sixfold concentration than in control medium (Fig. 6b). General tendency found in analysis of culture media was the strong relation between secretion of glycosides to the medium and their inside accumulation. However, in the case of certain lines, impact of media composition was evident. Lines $\mathrm{CH} 2$ and MC3 generally with low secretion efficiency improved releasing the glycosides twofold in the media supplemented with high concentration of edamine but without ammonium salt (MS4). On contrary, in line CC16, the secretion was inhibited by over standard level of lactalbumin hydrolysate. It was over tenfold and nearly sevenfold lower, respectively, for MS1-MS2 and for MS3-MS4 media.

\section{Hairy roots: effect of nitrate increase}

Positive correlation between mineral nitrogen form modification and OA derivatives suggested the further study of this issue. Media lacking the ammonium ions and containing potassium nitrate, as a sole inorganic nitrogen source, at $1 \times$ to $4.5 \times$ concentration of $1 / 2$ MS medium (Murashige and Skoog 1962) were used. Figure 7 shows the growth of two lines of hairy roots expressed as a dry weight. Line CC16 

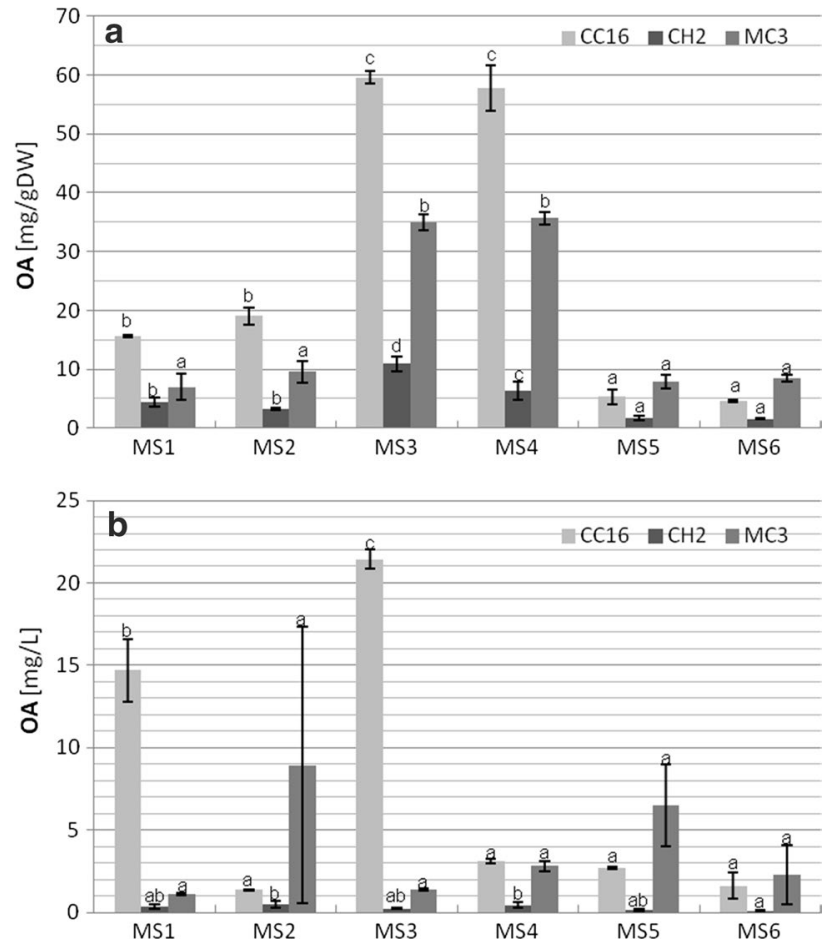

Fig. 6 Effects of media composition on OA accumulation in hairy root lines. Saponin content in tissue (a) and released to the media (b) determined after 30 days of culture. Mean \pm standard error of three replicates. Means with common letters within the line are not significantly different at $P \leq 0.05$ according to Fisher's multiple range test

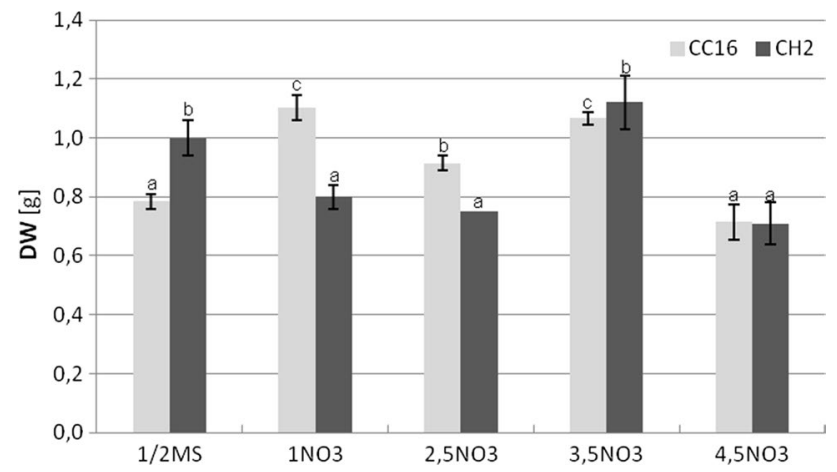

Fig. 7 Effects of nitrate concentration on hairy root lines growth in liquid medium. Values are mean $\pm \mathrm{SE}$ of three replications. Means with common letters within the lines are not significantly different at $P \leq 0.05$ according to Fisher's multiple range test

grows efficiently in the media with elevated level of nitrate in relation to control ( $1 / 2 \mathrm{MS})$ medium; however, some specific fluctuations of growth were observed. Removing of ammonium ions from the standard medium composition lowered the DW for $\mathrm{CH} 2$ (see column $1 \mathrm{NO}_{3}{ }^{-}$and $2.5 \mathrm{NO}_{3}{ }^{-}$on diagram Fig. 7) to rise over the control for $3.5 \mathrm{NO}_{3}{ }^{-}$and finally drop down at the highest concentration of $\mathrm{NO}_{3}{ }^{-}$. Elevated level of nitrate modulates hydration level of tissue, what was manifested by gradual increase of DW (\%): from $8.85 \%$ for $1 / 2$ MS to $13.21 \%$ for $4.5 \mathrm{NO}_{3}{ }^{-}$(Table 2). In CC16 line, $\%$ of DW increased, but the highest content of DW (\%) was noted for $1 \mathrm{NO}_{3}{ }^{-}-14.36 \%$ what represented 1.85 -fold of control culture. Morphological appearance of the first line supplemented with rising nitrate concentration was similar to control culture (Fig. 8a-c). Second line $(\mathrm{CH} 2)$ maintained that tendency (Fig. 8d-h); however, the highest concentration of nitrate reduced the growth and changed tissue morphology as the lateral roots were brownish and their number was reduced (Fig. 8h).

Triterpenic saponins accumulation expressed as an OA concentration in tissue (Fig. 9a) exhibited strong correlation to DW for $\mathrm{CC} 16$ line. Only the ammonium nitrate elimination $\left(1 \mathrm{NO}_{3}{ }^{-}\right)$improved saponins accumulation more than threefold, but without continuing in further concentrations. Different correlations for $\mathrm{CH} 2$ were found. This line demonstrated the linear increase of $\mathrm{OA}$ in tissue from 5.39 to $8.31 \mathrm{mg} \mathrm{g}^{-1} \mathrm{DW}$ until nitrate concentration reached 4.5 -higher value than in standard medium. Such nitrate concentration decreased metabolite concentration about $30 \%$ under the control culture productivity. Modification of nitrate content in culture media enabled us to find the conditions favorable for OA glycosides release from the tissue. In line CC16, saponin concentration increased in medium 2.5-and twice in relation to control, respectively, for $2.5 \mathrm{NO}_{3}{ }^{-}$and $3.5 \mathrm{NO}_{3}{ }^{-}$medium (Fig. 9b). Second line (CH2) despite containing over twofold, higher OA glycosides in tissue than $\mathrm{CC} 16$ (control conditions) released these compounds moderately. In optimal conditions $\left(3.5 \mathrm{NO}_{3}{ }^{-}\right)$, $\mathrm{CH} 2$ achieved $0.18 \mathrm{mg} \mathrm{L}^{-1}$, which was only $85 \%$ efficiency of control conditions.

\section{Hairy roots: effect of $\mathrm{NO}_{3}{ }^{-} / \mathrm{NH}_{4}{ }^{+}$ratio}

Standard MS medium (Murashige and Skoog 1962) contains $60 \mathrm{mM}$ of nitrogen, which is represented by potassium nitrate $(39.4 \mathrm{mM})$ and ammonium nitrate $(20.6 \mathrm{mM})$. Established hairy root cultures of marigold were maintained at $1 / 2$ MS, where macro-element concentrations were decreased by half and nitrate/ammonium ratio was almost 2 to 1 . In this kind of medium composition, both tested lines (CC 16 and $\mathrm{CH} 2)$ differed in the growth $(0.78 \pm 0.03$ and $0.93 \pm 0.07 \mathrm{~g}$ of DW, respectively) and saponin content ( $2.12 \pm 0.23$ and $4.39 \pm 0.20 \mathrm{mg} \mathrm{OA} \mathrm{g}^{-1} \mathrm{DW}$, respectively). The growth rate differences between those lines were stronger after the proposed nitrate/ammonium modification. Line $\mathrm{CH} 2$ decreased their growth in all used media modification: $44 \%(5: 1)$, 40\% (4:2) until 79\% (3:3) (Fig. 10). In contrary, line CC16 increased the DW in the first two cases: 36 and $64 \%$ for 5:1 and 4:2, respectively; however, equimolar concentration of nitrate/ammonium weakened the growth of hairy roots by 
Fig. 8 Effect of nitrate increase on hairy roots morphology, line CC16 (a-c): control (a), $2.5 \times$ $\mathrm{NO}_{3}^{-}(\mathbf{b}), 4.5 \times \mathrm{NO}_{3}^{-}$(c) line $\mathrm{CH} 2$ (d-h): control (d), $1 \times \mathrm{NO}_{3}$ (e), $2.5 \times \mathrm{NO}_{3}^{-}$(f) $3.5 \times \mathrm{NO}_{3}(\mathbf{g})$, and $4.5 \times \mathrm{NO}_{3}^{-}$(h)
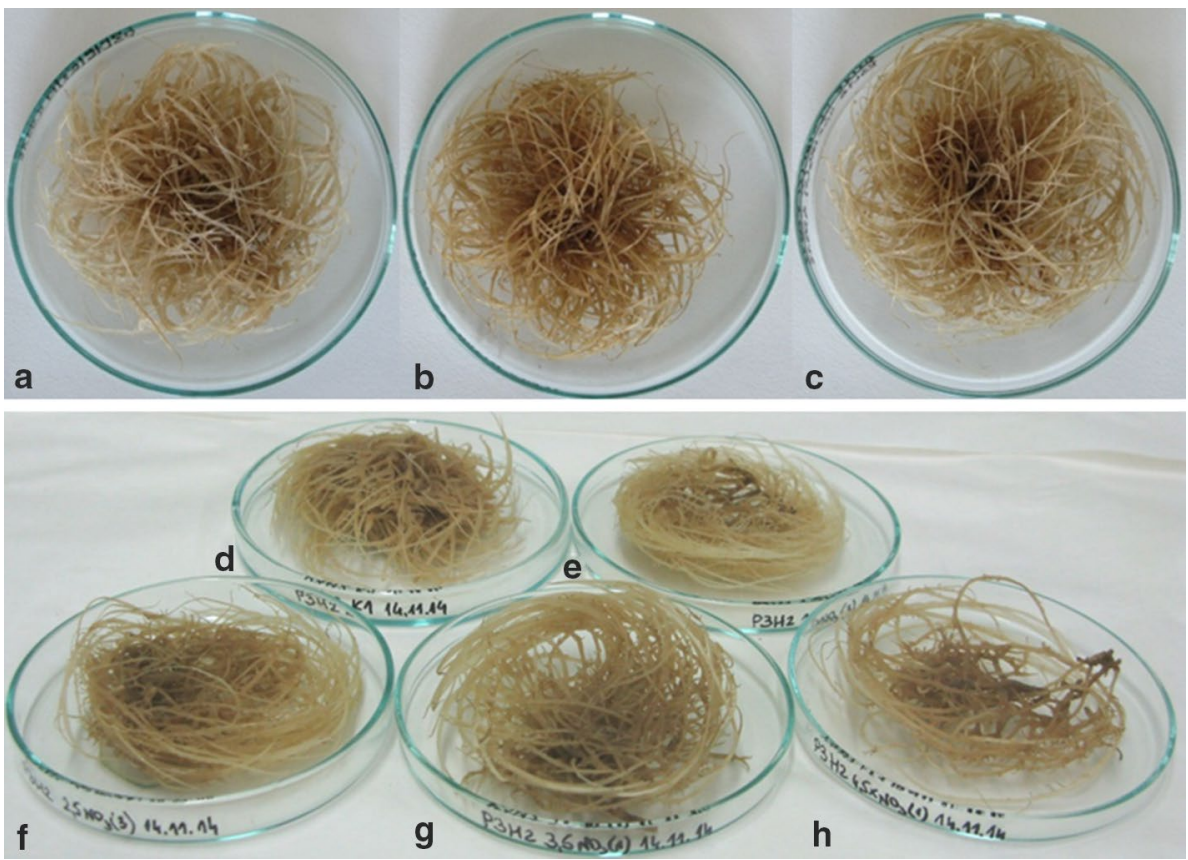
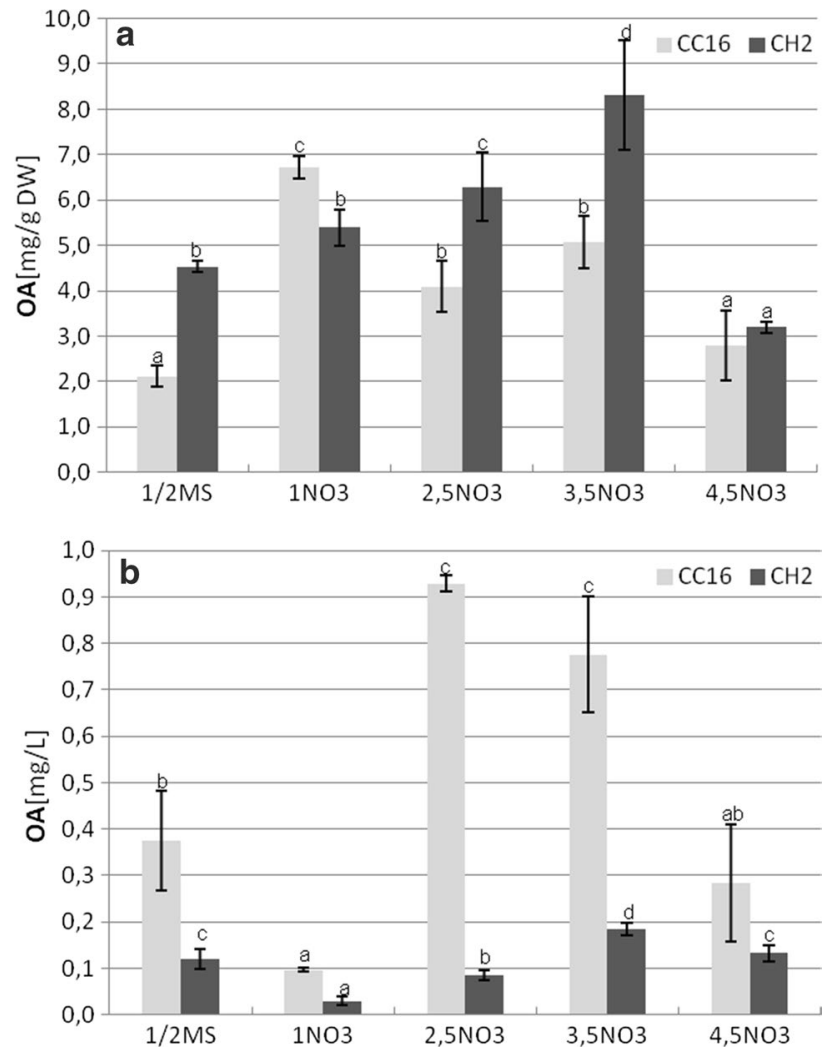

Fig. 9 Effects of nitrate concentration on OA accumulation in hairy root lines. Saponin content in tissue (a) and released to the media (b) determined after 30 days of culture. Mean \pm standard error of three replicates. Means with common letters within the line are not significantly different at $P \leq 0.05$ according to Fisher's multiple range test

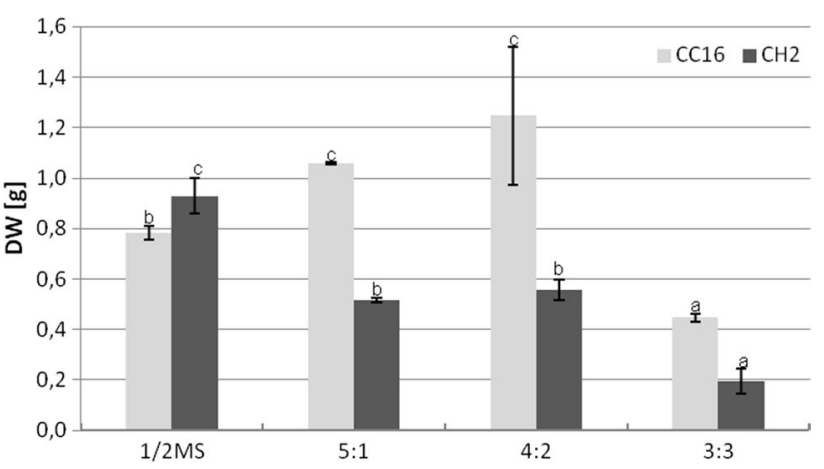

Fig. 10 Effects of $\mathrm{NO}_{3}{ }^{-} / \mathrm{NH}_{4}{ }^{+}$ratio on hairy root lines growth in liquid medium. Values are mean $\pm \mathrm{SE}$ of three replications. Means with common letters within the lines are not significantly different at $P \leq 0.05$ according to Fisher's multiple range test

58\%. Morphological appearance of two lines showed some differences mainly related to the hue and root thickness presented after the growth period in shaken flasks (Fig. 11). Line CC16 changed from pale yellow appearance in standard medium to straw colour in 5:1 (Fig. 11b) and 3:3 (Fig. 11d), whereas tissue from 4:2 was tawny (Fig. 11c). Hairy roots from 3:3 variant were thinner. Tissue of the line $\mathrm{CH} 2$ seemed to pale at 5:1 (Fig. 11f) and was clearly brighter at 3:3 medium (Fig. 11h).

Similar dependences of saponin content in tissue for both lines were noted (Fig. 12a). Highest triterpenic saponin quantity was measured for the $\mathrm{CH} 2$ line in the control medium. Proposed $\mathrm{NO}_{3}{ }^{-} / \mathrm{NH}_{4}{ }^{+}$modification resulted in average twofold lower accumulation of OA. Similar 


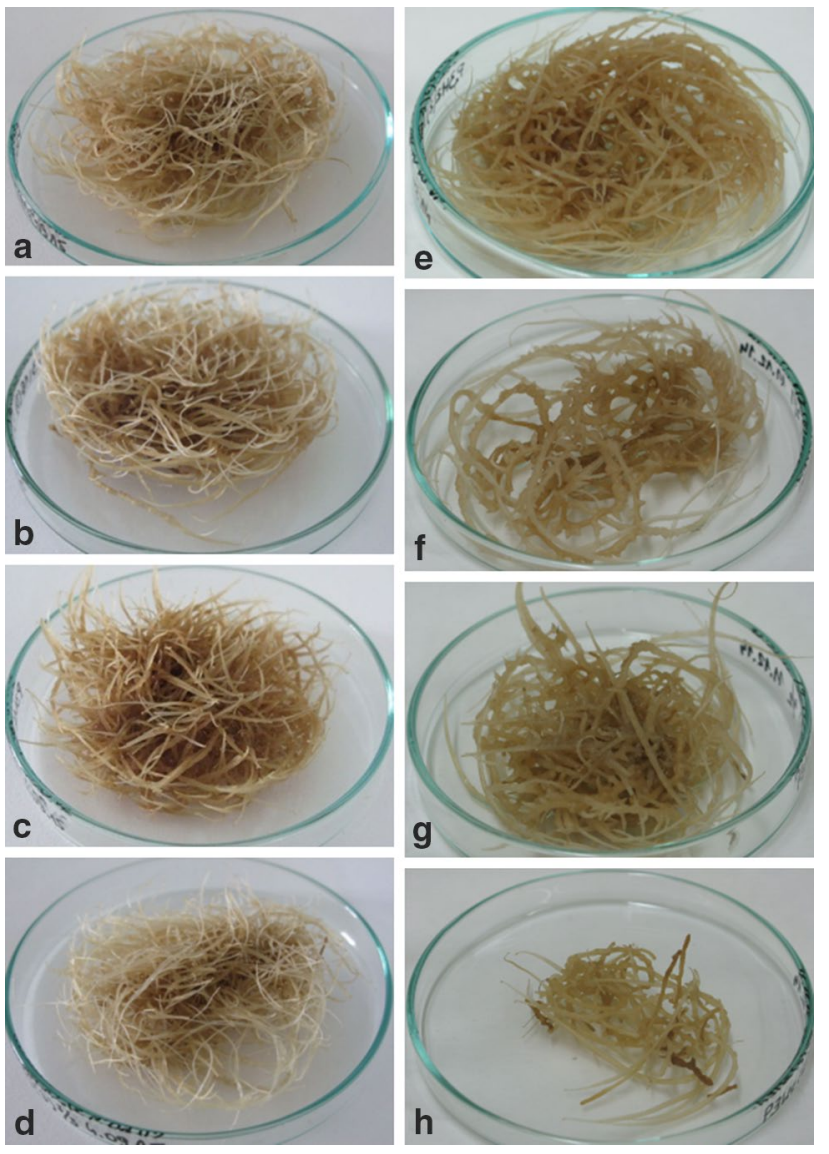

Fig. 11 Effect of different $\mathrm{NO}_{3}{ }^{-} / \mathrm{NH}_{4}{ }^{+}$ratio on hairy roots morphology, line CC16 (a-d): control (a), 5/1 (b), 4/2 (c), 3/3 (d), line CH2 (e-h): control (e), 5/1 (f), 4/2 (g), and 3/3 (h)

content levels were found for CC16 cultured in the media with nitrate:ammonium 5:1 ratio. Next two medium types showed gradual reduction of OA content below the control level for 3:3 ratio. More interesting effects were observed in the culture media. Two of the applied medium modifications resulted in 3.4- and 5.7-fold increase of saponin secretion to the medium, respectively, for 5:1 and 4:2 ratio (Fig. 12b). Second culture $(\mathrm{CH} 2)$ reduced the already low content of saponin in the medium from 0.14 to $0.04 \mathrm{mg} \mathrm{L}^{-1}$.

\section{Discussion}

Marigold C. officinalis despite the richness and variety of biologically active substances produced in its tissues still is poorly exploited on the area of modern plant biotechnology. One of the first reports, published in 2002 by our group, was concerned the seeking of explants and plant growth regulators suitable for culture initiation (Grzelak and Janiszowska 2002). The most efficient for callus induction on cotyledon and young leaf explants was auxin and
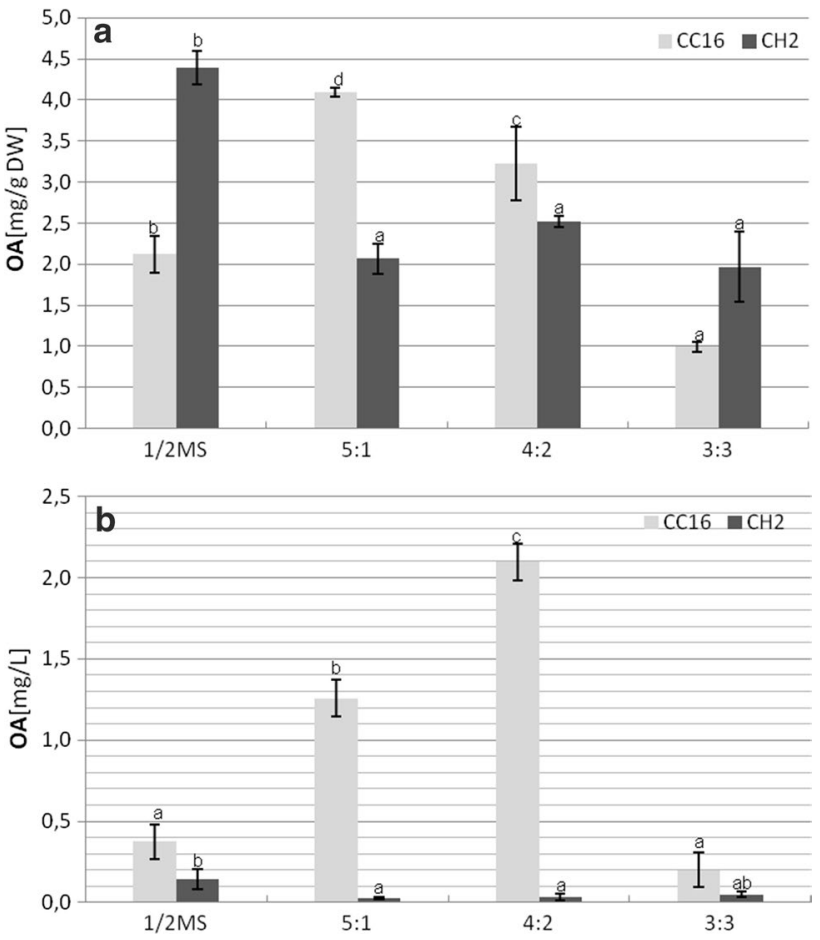

Fig. 12 Effects of $\mathrm{NO}_{3}{ }^{-} / \mathrm{NH}_{4}{ }^{+}$ratio on $\mathrm{OA}$ accumulation in hairy root lines. Saponin content in tissue (a) and released to the media (b) determined after 30 days of culture. Mean \pm standard error of three replicates. Means with common letters within the line are not significantly different at $P \leq 0.05$ according to Fisher's multiple range test

cytokinin compilation. Finally $2,4-\mathrm{D}$ and $2 \mathrm{iP}$ obtained the optimal growth and saponins concentration at $0.09 \mathrm{mg}$ per gram of FW. Marigold suspension culture used in the present research was initiated immediately (without an intervening callus phase) in liquid medium, where modified mineral nitrogen source $\left(2.5 \times \mathrm{KNO}_{3}, \mathrm{NH}_{4} \mathrm{NO}_{3}\right.$ omission-relative to $1 / 2 \mathrm{MS})$, tenfold organic nitrogen source, and only auxin (2,4D) obtained fast (2-6 months, depending on explant) culture initiation and stabilization from four seedlings explants.

Nitrogen source in both mineral forms: ammonium and nitrate, or other organic supplementation may act as factors important for initiation, growth, and metabolite accumulation in plant cultures. Results presented in this paper showed significantly that nitrate and organic source of nitrogen were essential for suspension culture initiation; nitrate strongly accelerates cell proliferation and generally saponins accumulation. However, tenfold higher concentration of organic nitrogen source, represented here by peptone from lactalbumin, decidedly inhibited synthesis of oleanolic acid glycosides. Supplementation with peptone accelerated the SC induction, mainly by the high of tryptophan-the auxin precursor-which interacts with nitrate and 2.4-D to enhance morphogenetic capacity of the explants. Peptone, which is a complex nitrogen source, contains wide range of 
proteins, peptides and free amino acids, likewise the mixture of sugars, fats, and vitamins. Many reports indicated the beneficial effect of some supplements to the medium on the content of secondary metabolites. Phenylalanine promoted taxol production in Taxus cuspidata cultures (Fett-Neto et al. 1994). The lactalbumin hydrolysate had no effect on alkaloid synthesis in Leonurus heterophylus Sw. suspension culture; however, the addition of L-proline increased alkaloid content significantly (Yang et al. 2008), definitely recognized as a stachydrine precursor (He and Wang 2005).

Established cultures expressed their morphogenetic capacity after removing aggregates to media lack of 2,4D. Somatic embryos grown in clusters and then developed distorted cotyledons contained chlorophyll. However, typical bipolar structure has never observed. The reasons for such abnormalities may be disorders of polar auxin transport in the arranged embryo. It is essential for the formation of meristems and plant growth. Number of reviews and reports focused on this topic: Yeung and Stasolla (2000), Souter and Lindsey (2000), van Berkel et al. (2013), Chen et al. (2010), and Elhiti and Stasolla (2011). Strong embryogenesis initiator, 2.4-D, was accumulated in tissue, where it was slowly deactivated. Tissue showed secondary proliferation after removing it to the regeneration medium. Embryo-like structure placed on the surface of solid medium was enveloped with callus which hampered their growth and differentiation.

Hairy root cultures of marigold can be maintained in both, solid and liquid $1 / 2$ MS media; however, liquid media obtain the fastest growth and possibility of analysis of triterpenic saponins released to the medium. The effect of nitrogen source on saponins accumulation and secretion in hairy roots of $C$. officinalis was reported for the first time. Lines selected for the evaluation of tenfold organic source of nitrogen (peptone from lactalbumin) showed different reactions depended additionally on mineral form of nitrogen used in media composition. Yu et al. (2000) reported that peptone, but in lower $\left(300 \mathrm{mg} \mathrm{L}^{-1}\right)$ concentration, gave a slight enhancement of ginsenosides synthesis for Panax ginseng hairy roots. This effect was confirmed for the bioreactor culture of $P$. ginseng reported by the same group (Sivakumar et al. 2005) without growth impairment.

Nitrogen, after the carbon and phosphorus, constitutes the basics components for plant growth and metabolism. Nitrate and ammonium salt being main sources of mineral nitrogen are known to have various influence on plant metabolite synthesis, transport, and distribution. Numerous reports indicate nitrate as a preferred form leading to increase rate of synthesis of important bioactive substances. Adventitious roots of $P$. ginseng in $\mathrm{Yu}$ et al. (2001) report and P. quinquefolium suspension culture (Zhong and Wang 1998) accumulated the highest amount of ginsenosides when nitrate ions were the sole source of nitrogen in cultivation medium. Similar conditions with low or complete absence of ammonium form intensified the synthesis of protopanaxadiol and protopanaxatriol (dammarane-type tetracyclic triterpenoids) derivatives in bioreactor hairy roots of $P$. quinquefolium (Kochan et al. 2016).

Nitrate/ammonium ratio seems to be fundamental factor, which is modified in numerous reports referring to plant micropropagation (Teixeira Da Silva 2013) or/and metabolite synthesis (Lee et al. 2011). As it was demonstrated in the current studies, the impact of this important macroelement should be determined individually for each genotype, type of in vitro culture and kind of metabolite. Nitrate as sole nitrogen source in the medium improved the growth rate of the Camptotheca acuminata cell culture; however, high ratio of ammonium:nitrate (5:1) was propitious for camptothecin (alkaloid, anticancer agent) accumulation (Pan et al. 2004). Shikonin, the first biotechnological product (dye, naphthoquinone derivative) obtained in industrial scale was promoted by reduced level of $\mathrm{NH}_{4}{ }^{+}$and increased level of $\mathrm{NO}_{3}{ }^{-}$in Lithospermum erythrorhizon suspension culture (Fujita et al. 1981). Predominance of ammonium ions for nitrate had a positive impact on berberine-antibacterial agent (alkaloid)—production in cell suspension culture of Thalictrum minus (Nakagawa et al. 1984). Triterpenic saponins are metabolites without nitrogen in their structure, although their accumulation in plant tissue remains under the strong impact of nitrate/ammonium ratio in mineral form. Such situation was result of assimilation and growth processes, genome background, and evolutionary aspect connected with ammonium toxicity/tolerance syndrome. Some authors suggest the changes of $\mathrm{pH}$ inside the cell compartments in response to assimilation of ammonium or nitrate, and therefore, regulation of enzymes in the final steps of saponins pathway can be achieved (Kochan et al. 2016). Marigold was included to a $\mathrm{NH}_{4}{ }^{+}$-sensitive plant (Britto and Kronzucker 2002), what was confirmed for suspension and hairy root cultures. Roots which have high responsiveness to nitrate-activator of $10 \%$ of plant transcriptome (Wang et al. 2003)—make the most complex area, where multidimensional relationship in metabolism creation impede their control. From the biotechnological point of view, it can be described as finding the compromise between satisfactory growth and cost-effective content of desired metabolite.

\section{Conclusions}

In current report, we first evaluated the effect of different nitrogen sources on the growth and oleanolic acid glycosides production in $C$. officinalis hairy roots and suspension cultures. Both types of cultures preferred nitrate as a mineral nitrogen source or coexistence with ammonium at $1 / 2$ MS ratio. Organic nitrogen source represented here by peptone from lactalbumin was crucial for suspension culture 
initiation; however, high concentration of this compound decreased saponins accumulation in suspension culture and growth rate in most of hairy root lines. Peptone effect on saponins accumulation and secretion in hairy root culture was depended on line, age of culture, and media composition. Elevated level of nitrate ions may increase rate of production of listed above metabolites in hairy roots, but the lines exhibited different toxicity levels of this macro element. Saponins secretion to the surrounding medium was generally harmonized with their accumulation inside the tissue; however, $\mathrm{NO}_{3}{ }^{-} / \mathrm{NH}_{4}{ }^{+}$ratio manipulation generated almost sixfold intensification of this effect.

Author contribution statement Conceived and designed the experiments: MD. Performed the experiments: MD. Analyzed the data: MD. Contributed reagents/materials/ analysis tools: MD, MM, and CP. Wrote the paper: MD. All authors read and approved the final manuscript.

Funding This study was supported by the State Committee for Scientific Research (KBN) through the Faculty of Biology University of Warsaw Intramural Grants BW: 1755-13 and 501/86-100007.

Open Access This article is distributed under the terms of the Creative Commons Attribution 4.0 International License (http://creativecomm ons.org/licenses/by/4.0/), which permits unrestricted use, distribution, and reproduction in any medium, provided you give appropriate credit to the original author(s) and the source, provide a link to the Creative Commons license, and indicate if changes were made.

\section{References}

Aoki T, Matsumoto H, Asako Y, Matsunaga Y, Shimomura K (1997) Variation of alkaloid productivity among several clones of hairy roots and regenerated plants of Atropa belladonna transformed with Agrobacterium rhizogenes 15834. Plant Cell Rep 16:282-286

Bensaddek L, Gillet F, Saucedo JEN, Fliniaux MA (2001) The effect of nitrate and ammonium concentrations of growth and alkaloid accumulation of Atropa belladonna hairy roots. J Biotechnol $85: 35-40$

Bloom AJ, Sukrapanna SS, Warner RL (1992) Root respiration associated with ammonium and nitrate absorption and assimilation by Barley. Plant Physiol 99:1294-1301

Britto DT, Kronzucker HJ (2002) $\mathrm{NH}^{+}{ }^{+}$toxicity in higher plants: a critical review. J Plant Physiol 159:567-584

Chashmi NA, Sharifi M, Karimi F, Rahnama H (2008) Enhanced production of tropane alkaloids by nitrate treatment in hairy root cultures of Atropa belladonna. J Biotechnol 136:55

Chen D, Ren Y, Deng Y, Zhao J (2010) Auxin polar transport is essential for the development of zygote and embryo in Nicotiana tabacum L. and correlated with ABP1 and PM $\mathrm{H}^{+}$-ATPase activities. J Exp Bot 61:1853-1867

Cui XH, Murthy HN, Wu CH, Paek KY (2010) Adventitious root suspension cultures of Hypericum perforatum: effect of nitrogen source on production of biomass and secondary metabolites. In Vitro Cell Dev Biol Plant 46:437-444
Deeb D, Gao X, Dulchavsky SA, Gautam SC (2008) CDDO-Me inhibits proliferation, induces apoptosis, down-regulates Akt, mTOR, NF-kappaB and NF-kappaB-regulated antiapoptotic and proangiogenic proteins in TRAMP prostate cancer cells. J Exp Ther Oncol 7:31-39

Długosz M, Wiktorowska E, Wiśniewska A, Pączkowski C (2013) Production of oleanolic acid glycosides by hairy root established cultures of Calendula officinalis L. Acta Biochem Pol 60:467-473

Doligalska M, Jóźwicka K, Kiersnowska M, Mroczek A, Pączkowski C, Janiszowska W (2011) Triterpenoid saponins affect the function of P-glycoprotein and reduce the survival of the free-living stages of Heligmosomoides bakeri. Vet Parasitol 179:144-151

Elhiti M, Stasolla C (2011) Ectopic expression of the Brassica SHOOTMERISTEMLESS attenuates the deleterious effects of the auxin transport inhibitor TIBA on somatic embryo number and morphology. Plant Sci 180:383-390

Elsayed HE, Akl MR, Ebrahim HY, Sallam AA, Haggag EG, Kamal AM, El Sayed KA (2015) Discovery, optimization and pharmacophore modeling of oleanolic acid and analogues as breast cancer cell migration and invasion inhibitors through targeting Brk/Paxillin/Rac1 axis. Chem Biol Drug Des 85:231-243

Fai YM, Tao CC (2009) A review of presence of oleanolic acid in natural products. Nat Prod Med 2:77-290

Fett-Neto AG, Stewart JM, Nicholson SA, Pennington JJ, DiCosmo F (1994) Improved taxol yield by aromatic carboxylic acid and amino acid feeding to cell cultures of Taxus cuspidata. Biotechnol Bioeng 44:967-971

Fujita Y, Hara Y, Ogino T, Suga C (1981) Production of shikonin derivatives by cell suspension cultures of Lithospermum erythrorhizon. I. Effects of nitrogen sources on the production of shikonin derivatives. Plant Cell Rep 1:59-60

Fukushima EO, Seki H, Ohyama K, Ono E, Umemoto N, Mizutani M, Saito K, Muranaka T (2011) CYP716A subfamily members are multifunctional oxidases in triterpenoid biosynthesis. Plant Cell Physiol 52:2050-2061

Grzelak A, Janiszowska W (2002) Initiation and growth characteristic of suspension culture of Calendula officinalis cells. Plant Cell Tissue Organ Cult 71:29-40

He LQ, Wang XS (2005) Synthesis of stachydrine. Chem World 5:296-298

Janiszowska W, Kasprzyk Z (1977) Intracellular distribution and origin of pentacyclic triterpenes in Calendula officinalis leaves. Phytochemistry 16:1919-1923

Kashiwada Y, Wang HK, Nagao T, Kitanaka S, Yasuda I, Fujioka T, Yamagishi T, Cosentino LM, Kozuka M, Okabe H, Ikeshiro Y, Hu CQ, Yeh E, Lee KH (1998) Anti-AIDS agents. 30. Anti-HIV activity of oleanolic acid, pomolic acid and structurally related triterpenoids. J Nat Prod 61:1090-1095

Kochan E, Szymczyk P, Kuźma Ł, Szymańska G (2016) Nitrogen and phosphorus as the factors affecting ginsenoside production in hairy root cultures of Panax quinquefolium cultivated in shake flasks and nutrient sprinkle bioreactor. Acta Physiol Plant 38:149

Laszczyk MN (2009) Pentacyclic triterpenes of the lupine, oleanane and ursane group as tools in cancer therapy. Planta Med 75:1549-1560

Lee Y, Lee DE, Lee HS, Kim SK, Lee VS, Kim SH, Kim MW (2011) Influence of auxins, cytokinins, and nitrogen on production of rutin from callus and adventitious roots of the white mulberry tree (Morus alba L.). Plant Cell Tissue Organ Cult 105:9-19

Liby K, Royce DB, Williams CR, Risingsong R, Yore MM, Honda T, Gribble GW, Dmitrovsky E, Sporn TA, Sporn MB (2007) The synthetic triterpenoids CDDO-methyl ester and CDDO-ethyl amide prevent lung cancer induced by vinyl carbamate in $\mathrm{A} / \mathrm{J}$ mice. Cancer Res 67:2414-2419

Lisiak N, Paszel-Jaworska A, Bednarczyk-Cwynar B, Zaprutko L, Kaczmarek M, Rybczyńska M (2014) Methyl 
3-hydroxyimino-11-oxoolean-12-en-28-oate (HIMOXOL), a synthetic oleanolic acid derivative induces both apoptosis and autophagy in MDA-MB-231 breast cancer cells. Chem Biol Interact 208:47-57

Murashige T, Skoog F (1962) A revised medium for rapid growth and bioassays with tobacco tissue cultures. Physiol Plant 15:473-497

Nakagawa K, Konagai A, Fukui H, Tabata H (1984) Release and crystallization of berberine in the liquid medium of Thalictrum minus cell suspension cultures. Plant Cell Rep 3:254-257

Näsholm T, Kielland K, Ganeteg U (2009) Uptake of organic nitrate by plants. New Phytol 182:31-48

Pan XW, Xu HH, Liu X, Gao X, Lu YT (2004) Improvement of growth and camptothecin yield by altering nitrogen source supply in cell suspension cultures of Camptotheca acuminata. Biotechnol Lett 26:1745-1748

Praveen N, Murthy HN (2013) Withanolide A production form Withania somnifera hairy root cultures with improved growth by altering the concentrations of macro elements and nitrogen source in the medium. Acta Physiol Plant 35:811-816

Praveen N, Murthy HN, Chung IM (2011) Improvement of growth and gymnemic acid production by altering the macro elements concentration and nitrogen source supply in cell suspension cultures of Gymnema sylvestre R. Br. Ind Crops Prod 33:282-286

Rajashekaran T, Rajendran I, Ravishankar GA, Venkataraman LV (1991) Influence of nutrient stress on pyrethrin production in cultured cells of pyrethrum (Chrysanthemum cinerariaefolium). Curr Sci 60:705-707

Rios JL (2010) Effects of triterpenes on the immune system. J Ethnopharmacol 128:1-14

Simonsen JL, Ross WCJ (1957) The terpenes: the triterpenes and their derivatives, vol 5: hydroxy acids, hydroxy lactones, hydroxyaldehydo acids, hydroxyketo acids and the stereochemistry of the triterpenes. Cambridge University Press, Cambridge

Sivakumar G, Yu KW, Hahn EJ, Paek KY (2005) Optimization of organic nutrients for ginseng hairy roots production in large-scale bioreactors. Curr Sci 89:641-649

Souter M, Lindsey K (2000) Polarity and signaling in plant embryogenesis. J Exp Bot 51:971-983

Sporn MB, Liby KT, Yore MM, Fu L, Lopchuk JM, Gribble GW (2011) New synthetic triterpenoids: potent agents for prevention and treatment of tissue injury caused by inflammatory and oxidative stress. J Nat Prod 74:537-545

Święcicka M, Filipecki M, Lont D, Van Vliet J, Qin L, Goverse A, Bakker J, Helder J (2009) Dynamics in the tomato root transcriptome on infection with the potato cyst nematode Globodera rostochiensis. Mol Plant Pathol 10:487-500

Szakiel A, Ruszkowski D, Janiszowska W (2005) Saponins in Calendula officinalis L. - structure, biosynthesis, transport and biological activity. Phytochem Rev 4:151-158
Szakiel A, Ruszkowski D, Grudniak A, Kurek A, Wolska K, Doligalska M (2008) Antibacterial and antiparasitic activity of oleanolic acid and its glycosides isolated from marigold (Calendula officinalis). Planta Med 74:1709-1715

Szakiel A, Pączkowski C, Henry M (2011) Influence of environmental abiotic factors on the content of saponins in plants. Phytochem Rev 10:471-491

Taylor AR, Bloom AJ (1998) Ammonium, nitrate and proton fluxes along the maize root. Plant Cell Environ 21:1255-1263

Teixeira Da Silva JA (2013) Ammonium to nitrate ratio affects PLB formation of hybrid Cymbidium. J Ornam Hortic Plants 3:155-160

van Berkel K, de Boer RJ, Scheres B, ten Tusscher K (2013) Polar auxin transport: models and mechanisms. Development 140:2253-2268

Wang R, Okamoto M, Xing X, Crawford NM (2003) Microarray analysis of the nitrate response in Arabidopsis roots and shoots reveals over 1,000 rapidly responding genes and new linkages to glucose, trehalose-6-phosphate, iron and sulfate metabolism. Plant Physiol 132:556-567

Wang X, Ye X, Liu R, Chen HL, Bai H, Liang X, Zhang XD, Wang Z, Li W, Hai CX (2010) Antioxidant activities of oleanolic acid in vitro: possible role of Nrf2 and MAP kinases. Chem Biol Interact 184:328-337

Wiktorowska E, Długosz M, Janiszowska W (2010) Significant enhancement of oleanolic acid accumulation by biotic elicitors in cell suspension cultures of Calendula officinalis L. Enzyme Microbiol Technol 46:14-20

Yang J, Gong ZC, Tan X (2008) Induction of callus and extraction of alkaloid from Yi Mu Cao (Leonurus heterophylus $\mathrm{Sw}$.) culture. Afr J Biotechnol 7:1157-1162

Yeung EC, Stasolla C (2000) Somatic embryogenesis-apical meristem formation and conversion. Korean J Plant Tissue Cult 27:253-258

Yu KW, Gao WY, Son SH, Peak KY (2000) Improvement of ginsenoside production by jasmonic acid and some other elicitors in hairy root culture of ginseng (Panax ginseng C.A. Meyer). In Vitro Cell Dev Biol Plant 36:424-428

Yu KW, Gao WY, Hahn EJ, Paek KY (2001) Effects of macroelements and nitrogen source on adventitious root growth and ginsenoside production in ginseng (Panax ginseng CA Meyer). J Plant Biol 44:179-184

Zhang J, Gao WY, Wang J, Li XL, Xiao PG (2011) Improvement of growth and periplocin yield of Periploca sepium adventitious root cultures by altering nitrogen source supply. Chin Herb Med 3:226-231

Zhong JJ, Wang SJ (1998) Effects of nitrogen source on the production of ginseng saponin and polysaccharide by cell cultures of Panax quinquefolium. Process Biochem 33:671-675 